\title{
Network analysis as a tool for quantifying the dynamics of metacoupled systems: an example using global soybean trade
}

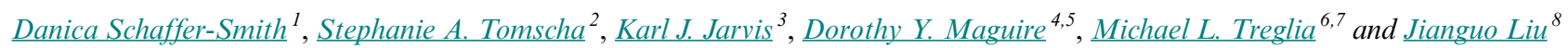

\begin{abstract}
The metacoupling framework provides grounds for characterizing interactions within and between coupled human and natural systems, yet few studies quantify the nuances of these systems. Network analysis is a powerful and flexible tool that has been used to quantify social, economic, and ecological systems. Our objective was to evaluate the utility of network analysis for quantifying metacoupled systems by assessing global soybean trade among 217 countries from 1986 to 2013 . We identified and quantified sending and receiving systems, subnetworks and flow pathways, changes over time and across scales, feedbacks, and associations between trade and tropical deforestation. Although a total of 165 distinct cliques were identified within the network, a few key players were disproportionately influential in the 2872 partnerships, including Brazil (37.5\%), China (48.6\%), and the USA (72.3\%). Total network density increased five-fold over the study period with an increasingly smaller set of countries heavily engaged in trade, posing sustainability and food security concerns. We found evidence of a positive feedback where countries with established trade partnerships were more likely to expand trade relationships over the study period. Trade patterns were not explained by regional or continental geography, highlighting limitations of neighborhood analyses commonly used in ecology. We also found evidence of a link between soybean trade and tropical deforestation; in pantropical countries participating in soybean trade, cumulative soybean exports for the period 2000-2012 were strongly associated with remotely sensed estimates of forest loss by country $(\mathrm{Rsq}=0.35, \mathrm{p}<0.0001)$. We demonstrated that network analyses can be used to quantitatively assess relationships between metacoupled social-ecological systems. Increased data access and platforms for integrating diverse data sources using multidisciplinary tools will be key to pushing the boundaries of quantitative metacoupled systems research.
\end{abstract}

Key Words: agriculture; Brazil; China; connectivity; coupled human and natural systems; export; graph theory; import; social-ecological systems; telecoupling; USA

\section{INTRODUCTION}

The world is becoming increasingly connected, with human and natural systems coupled over great distances producing localized consequences. The telecoupling framework has established a foundation for understanding the dynamics and consequences of social-ecological interactions over distances (Liu et al. 2013), along with well-defined terminology to conceptualize distinct parts of these systems. Telecoupled systems are composed of sending, receiving, and spillover systems, which may each have unique causes, agents, and effects that must be considered. These systems may be hierarchically structured, with interactions spanning multiple scales, through connecting flows and feedbacks. Furthermore, the framework has recently been expanded to encompass metacoupling, which simultaneously incorporates interactions within and between multiple spatially proximate and distant coupled human and natural systems (Liu 2017). While interactions occurring entirely within a focal system of interest are considered as intracoupling, intercoupling may also exist between two or more systems through pericoupling linking nearby systems, or telecoupling linking distant systems. Despite conceptual advances in the field, techniques for quantifying the dynamics of metacoupled systems are still in development.

Much of the telecoupling research to date has focused on qualitatively identifying sending, receiving, and spillover systems
(Deines et al. 2016, Liu et al. 2016), and identifying potential drivers, such as global trade of agricultural and forest products (Liu et al. 2013), energy trade (Fang et al. 2016), sand trade (Torres et al. 2017), water transfers (Yang et al. 2016), species migration (Hulina et al. 2017), conservation (Carter et al. 2014), fisheries (Carlson et al. 2017), and economic development (Yang et al. 2016). Application of the telecoupling framework has identified key research gaps (e.g., Liu et al. 2016) and governance needs (Hulina et al. 2017), and has also generated unexpected findings and new hypotheses (e.g., Sun et al. 2018). However, even for wellknown examples of telecoupled systems, rarely have social and ecological interactions and dynamics over time and space been simultaneously considered using quantitative approaches.

Global soybean trade was one of the first case studies conceptualized as a telecoupled system with broad social and ecological consequences (Fig. 1), yet previous research has focused mainly on qualitative description (e.g., Nepstad et al. 2006) and soybean trade has not yet been considered as a metacoupled system. Global land area for soybean production doubled over the past three decades, while the land area for most other crops has remained relatively constant (Reenberg and Fenger 2011). Increasing global demand for soybeans and their derivatives has been fueled by population growth, increased wealth, and higher meat consumption (Gasparri et al. 2015). Although China, where soybeans were domesticated thousands

\footnotetext{
${ }^{1}$ Nicholas School of the Environment, Duke University, Durham, NC, ${ }^{2}$ School of Biological Sciences, Victoria University of Wellington, New Zealand, ${ }^{3}$ Department of Biology, Southern Utah University, Cedar City, UT, ${ }^{4}$ USDA-ARS European Biological Control Laboratory, Montpellier, France, ${ }^{5}$ Department of Biology, Boise State University, Boise, ID, ${ }^{6}$ New York City Program, The Nature Conservancy, New York, NY, ${ }^{7}$ Department of Biological Science, University of Tulsa, Tulsa, OK, ${ }^{8}$ Center for Systems Integration and Sustainability, Michigan State University, East Lansing, MI
}

Erratum: The figure captions in the original publication of this paper were incorrect and were replaced with the proper captions on 7 February 2019 . 
Fig. 1. The soybean metacoupled system, including sending systems (yellow), receiving systems (green), and spillover systems (blue), with arrows showing the connections that occur within and between systems.

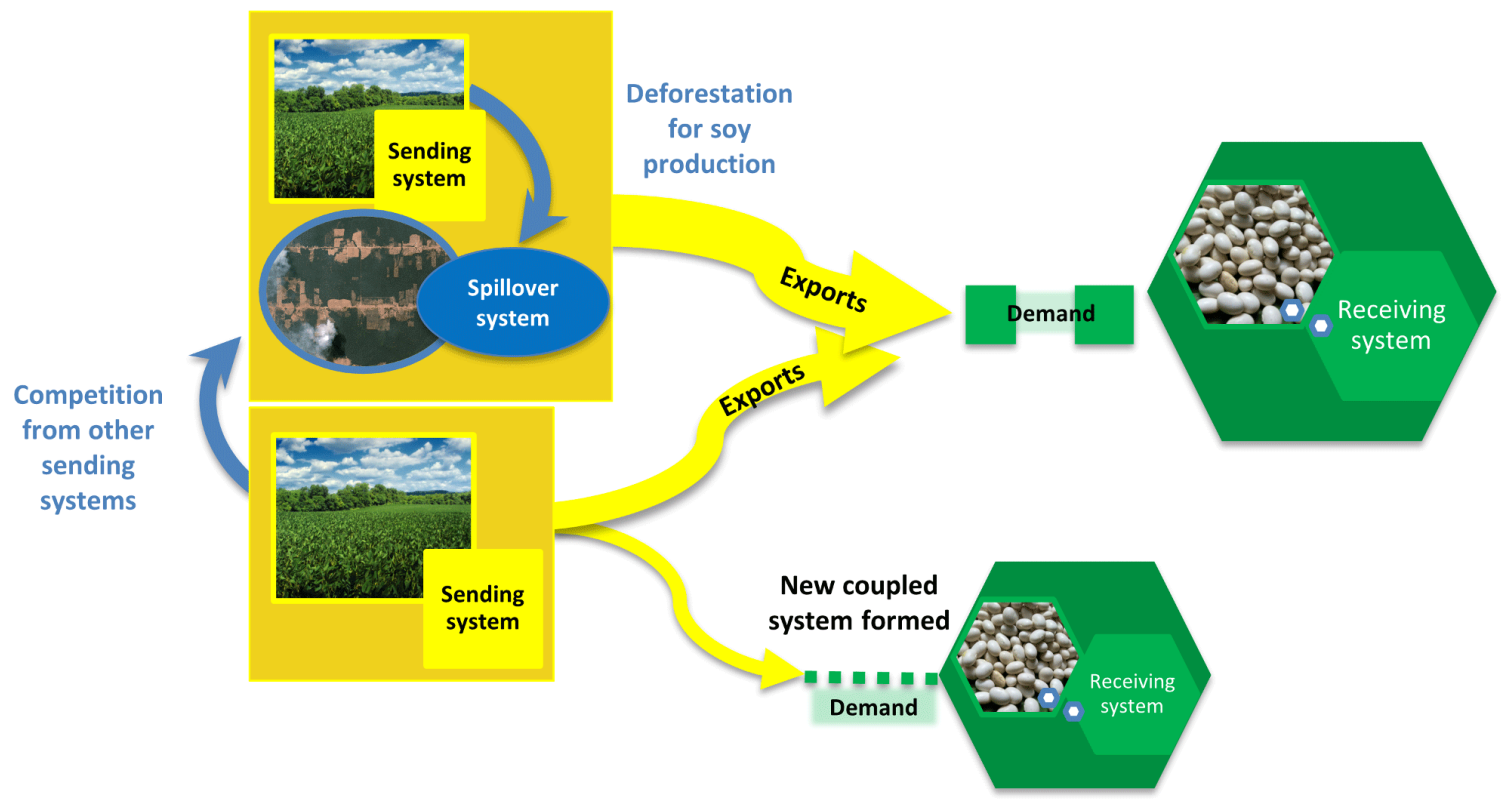

of years ago, was historically the top soybean exporter (sending system; Sun et al. 2015), the USA dramatically increased production and overtook China as the dominant contemporary sending system (Reenberg and Fenger 2011). Notable production increases then proceeded in Brazil and Argentina, displacing previously forested landscapes, driven in part by government subsidies, external investments in road infrastructure, and unclear land tenure (Macedo et al. 2012). Brazil's soybean exports recently surpassed those of the USA, and its southern hemisphere production can complement or compete with production in the USA (spillover system; Liu et al. 2015a). Paradoxically, China has emerged as the dominant importer (receiving system), appropriating $>50 \%$ of global soybean exports and sourcing $>$ $80 \%$ of the soybean it consumes from outside its borders in recent years (Reenberg and Fenger 2011, Liu et al. 2015a, b). Soybean trade patterns were quantified in a previous study (Kastner et al. 2014), yet, the authors suggested that results contradicted their knowledge of the system, indicating an ongoing need for appropriate methods to quantify the dynamics of the soybean metacoupled system (SMS).

Network analysis can be used to quantify functional connections between distant systems and between neighboring systems, and is well-suited to address a range of complexities possible in metacoupled systems such as the SMS (Box 1; Urban and Keitt 2001, Barrat et al. 2008, Fortin et al. 2012). Flexible in disciplinary application, network analysis has been vetted in a wide range of contexts. Previous work has typically focused on the human domain (Iapadre and Tajoli 2014, del Río-Chanona et al. 2017), including social relationships (Fletcher et al. 2011, Mikusiński et al. 2013, De Benedictis et al. 2014), international finance (Contreras and Fagiolo 2014) and economic development (Shutters and Muneepeerakul 2012), commodity supply chains (Acemoglu et al. 2012, Mastrandrea et al. 2014, Possamai et al. 2015, Shen et al. 2015, Cai and Song 2016), transnational land acquisitions (Seaquist et al. 2014), virtual water trade (Dalin et al. 2011), transportation networks (Carvalho et al. 2012), human migration (Davis et al. 2013), and the spread of toxins (BuiKlimke et al. 2014) and diseases (Lentz et al. 2016). Studies of commodity trading have extensively employed network analysis methods including input-output analysis (e.g., Roy and Hewings 2009, Acemoglu et al. 2012, Aldasoro and Angeloni 2013, Contreras and Fagiolo 2014), open flow networks (e.g., Shen et al. 2015), and the use of null network models (e.g., Mastrandrea et al. 2014). Network analysis also shows promise for investigating social-ecological associations (e.g., Bodin and Crona 2009, Rathwell and Peterson 2012, Schiller et al. 2014). Although some researchers have reported ecological effects of international trade (e.g., DeFries et al. 2010, Lenzen et al. 2012, Moran and Kanemoto 2017), network analyses of trade have not often addressed effects on ecosystems, and have not been employed using the metacoupling framework to consider dynamics of feedbacks and spillover systems.

Many aspects of the SMS remain undescribed, and some wellstudied linkages could be quantified in greater detail using network analysis methods. An entire metacoupled system can be represented as a network with a vast array of metrics available to evaluate dynamics at multiple hierarchical levels from subnetworks (intercoupled subsystems) connected by key flow pathways, to the level of individual nodes, e.g., agents such as individual countries or decision makers, operating within an intracoupled system. A network analysis approach can be used to delineate loosely or tightly connected metacoupled communities that generate underlying structure within the broader network, which may each have social-ecological properties and implications that have yet to be considered for the SMS. The shared attributes of nodes in these communities may also reveal key drivers underlying the establishment and maintenance of metacoupled systems. Networks can also be time- 
ordered (Kempe et al. 2002, Blonder et al. 2012); assessment of the relative strengths of complex connections among and within sending, receiving, and spillover systems over time may help to shed light on some of the most poorly understood aspects of metacoupled systems (Liu et al. 2013, Liu 2017).

Long-term trends and feedbacks in the SMS, which may amplify or dampen metacoupling effects, have not been thoroughly studied. As in many other metacoupled systems, the limitations of geographic distance for nutrient, material, and organism flows across social and ecological networks (Fahrig 2003, Gonzalez 2009, Lee and Kwan 2011) have been overcome by faster communication and transportation (Fletcher et al. 2011, Mikusiński et al. 2013, Eakin et al. 2014), defying classic spatial assumptions and posing challenges to understanding of complex processes such as land use change (Friis et al. 2016). Legacies, or the phenomenon in which historical patterns continue to explain current conditions, may also be crucial to understanding contemporary characteristics of metacoupled systems; in many cases, current observations of landscape patterns have been linked to human and natural disturbance history (Turner 2005). This can be explored at the scale of an individual node or edge, for example to determine whether attributes in one time step predict conditions in the future. More complex feedbacks can also be examined, such as the effect of flows between key communities of interest on the attributes of sending, receiving, or spillover system nodes of interest.

Insights into multiscale effects in both spatial and temporal dimensions are needed to develop a better understanding of the SMS, and other metacoupled systems. Taking a broad view of a system accounts for important drivers and effects from the local to landscape scale (Turner et al. 1989, Wiens 1989) and even to global scales (Cash et al. 2006). Subtle changes at one scale may produce feedback effects that are amplified over time, and may be experienced locally, in a nearby system, or within a spatially distant system, and thus require a metacoupling perspective (Liu 2017). This scaling can be considered using network analysis methods by analyzing dynamics between nodes using the finest spatial grain available, e.g., municipalities, and also at the level of aggregated countries and regions that may interact with one another in metacoupled systems.

Spillover systems, which may interact with sending and receiving system dynamics, are perhaps the least well studied aspect of the SMS and other metacoupled systems. Effects on, or of, spillover systems may occur across hierarchical levels and across scales. For example, previous studies of the SMS have considered the USA post hoc as a spillover system affected by emerging soybean trade markets (e.g., Liu et al. 2015b). As global demand for soybean continues to rise (Gasparri et al. 2015), and policies are working to prevent further degradation of the Amazon rain forest (Gibbs et al. 2015), technology transfer may enable new production frontiers in locations with appropriate soybean growing conditions, such as South Africa (Sinclair et al. 2014, Gasparri et al. 2015). Established sending countries may have to respond to increased competition from these nascent sending systems by diversifying their trade partnerships (Liu et al. 2015b).

Linkages between the social and ecological dimensions of the SMS have been proposed, but have not been thoroughly quantified. In particular, the arc of deforestation in the Brazilian Amazon has in large part been attributed to soybean trade
(Fearnside 2001, Reenberg and Fenger 2011, Lathuillière et al. 2014, Liu et al. 2015a), yet the relationship has not been quantified within the metacoupling framework. Tropical forest loss has consequences for local ecosystem services, e.g., water quality degradation (Foley et al. 2005) and livelihoods (Vittor et al. 2006), as well as global biodiversity (Gibson et al. 2011), and climate regulation (Asner et al. 2010). Though deforestation in Brazil declined substantially in the late 2000s because of policy changes encouraging land intensification in the Amazon, this displaced land conversion for soybean into the cerrado (Dou et al. 2018) to meet demands from a growing consumer base (Macedo et al. 2012, Rosa et al. 2012). Better understanding the causes of these effects could aid in policy development, for example, to avoid simple displacement of impacts to ever-expanding cultivation areas.

Our objective is to evaluate the utility of network analysis for quantifying social-ecological dynamics of the SMS in space and time. Specifically, we demonstrate the application of selected network analysis methods to address several key questions: (1) What are the most important sending and receiving systems and key flow pathways? (2) How have key sending and receiving systems and flow pathways changed over time? (3) Have past trade partnerships had a positive feedback on future trade partnerships? (4) To what extent have cross-scale dynamics from country to continental levels affected soybean trade patterns? (5) What spillover effects have emerging soybean sending systems had on the USA's role as an established dominant sending system? (6) To what extent have ecological impacts occurred in tropical forests, e.g., deforestation, on account of soybean trade? This work demonstrates a new application of network analysis to gain novel insights into previously understudied aspects of the SMS, and contributes to the growing body of literature showcasing the value of network analyses for analyzing complex social-ecological systems (Schiller et al. 2014).

\section{METHODS}

To assess social and ecological dynamics of the SMS, we assembled multiple open access datasets including soybean trade flows between countries, as well as country income and forest cover attributes by country. We completed all data analyses in the open source R statistical computing environment (R Core Team 2017). Data compilation was completed using the countrycode package (Arel-Bundock 2014). We used the igraph (Csardi and Nepusz 2006) and network (Butts 2008a) packages to construct the network, and ggplot2 (Wickham 2009) and GGally (Schloerke et al. 2016) to generate georeferenced network visualizations. Important nodes, edges, and flow paths connecting subnetwork groups were identified using the igraph (Csardi and Nepusz 2006) and sna (Butts 2008b) packages. Temporal analyses were executed with $\mathrm{R}$ packages networkDynamic (Butts et al. 2016) and tsna (Bender-deMoll and Morris 2016), cross-scale dynamics were assessed with the ergm package (Hunter et al. 2008), and the MuMin package was used for model selection and model averaging functions in the assessment of trade spillover effects (Bartoń 2018).

\section{Data preparation and network generation}

We harmonized datasets to account for slight differences in naming conventions and geopolitical changes over the study period, identifying each country by its ISO 3166 standard alpha-2 code. For simplicity, and to maximize the consistency of the historical record, we combined countries that have more recently 
split apart, and we did not separately consider territories or provinces. For example, we considered Hong Kong and China as one system for the full time series.

\section{Global soybean trade data}

The FAOSTAT trade database provides a consistent long-term data source to represent flows in the SMS (Food and Agriculture Organization of the United Nations 2016). We downloaded all available annual soybean trade data in terms of both volume and value (US\$) from 1986 to 2013 (Department of Economic and Social Affairs Statistics Division 2010, Food and Agriculture Organization of the United Nations 2016). Soybean trade data does not account for all global soybean production because soybean produced and consumed domestically is not captured. Following data harmonization, we retained soybean trade data for 217 countries over the entire time series.

\section{Deforestation and income data}

To demonstrate the utility of network analysis for evaluating multiple facets of the SMS, we integrated additional datasets representing both social and ecological attributes for pantropical countries participating in soybean trade. First, we incorporated annual estimates of forest loss from a $30-\mathrm{m}$ resolution satellitebased forest loss dataset for 2000-2012 (Hansen et al. 2013). This dataset was further processed by Austin et al. (2017) to summarize the annual loss of forest with $>50 \%$ tree cover for each country in the pantropics, considering each contiguous clearing in a given year as a unique deforestation event. To represent socioeconomic well-being in pantropical countries, we also included country income categories (low, lower middle, upper middle, or high income; The World Bank 2017). The full suite of data was available for 100 pantropical countries participating in soybean trade for the period 2000-2012 (Table A1.1).

\section{Network representation}

We represented the individual countries as the nodes in a directed spatial network, based on the geographic centroid coordinates (latitude/longitude) for each country. Edges between node pairs were weighted by the value of soybean exports (US\$) transferred between each origin and destination country in each year from 1986 to 2013. For the subset of 100 pantropical countries with available data, we also included as node attributes the estimates of deforestation and income category by country for the period 2000-2012. Although the value of soybean traded, a function of both volume and price, is not equivalent to production or land use dedicated to soybean, it may serve as a useful proxy for these attributes. For the pantropical countries that exported soybean 2000-2012, there was a significant association between export value and production volume when data were log (base 10) transformed $\left(\operatorname{adj} . \mathrm{r}^{2}=0.58, \mathrm{p}<0.0001\right.$; Table A1.1).

\section{Analysis}

Once the network was created, we applied a set of quantitative network analysis methods to address the following key questions about the SMS.

\section{Q: What are the most important sending and receiving systems and key flow pathways?}

Network analysis can assist in describing and quantifying the complexity and structure of relationships in the SMS. Using trade data from the most recent year (2013), we first identified the most important sending systems (net exporters) and receiving systems (net importers) by ranking country nodes in terms of their degree. We also assessed the directionality and strength of edges connecting nodes in terms of the value (US\$) of soybean traded between any two partners.

In addition to characterizing dynamics of specific nodes and edges, we examined the roles of key nodes in assortativity, or the patterns of how nodes are connected to each other (Newman 2003). For assortative networks, nodes with similar attributes, e.g., degree or spatial location, preferentially connect to one another, as is often observed in social networks. In contrast, in a disassortative network, more isolated nodes are linked into the broader system through highly connected hub nodes, as occurs in many technological and biological networks (Newman 2003). The assortativity coefficient is the Pearson correlation coefficient $r$; where $r>0$ indicates an assortative network, $r<0$ indicates a disassortative network, and $\mathrm{r}=0$ is an uncorrelated network (Newman 2003). For the entire SMS in 2013, we computed assortativity based on node degree.

Subnetwork structure can be characterized in more detail by identifying communities, components, and cliques. Numerous detection algorithms are available, including hierarchical clustering based on node similarity, and ranking partitions between communities using measures such as modularity (Girvan and Newman 2002, Fortunato 2010). Examining connected components and cliques within a network in terms of their size and membership of specific nodes can also provide insight into metacoupled system structure (Fortunato 2010). A strongly connected component is defined by the existence of directed flow from node a to node $b$, and directed flow from node $b$ to node $a$, whereas a clique comprises a set of adjacent nodes that are connected by at least one edge in either direction. We executed multiple approaches to detect communities, including the Newman-Girvan algorithm, which removes edges with high betweenness centrality to separate communities (Girvan and Newman 2002), a greedy algorithm that assesses partition quality based on modularity (Clauset et al. 2004), and Louvain clustering, which iterates node community assignment until total modularity cannot be improved (Blondel et al. 2008). Both the greedy modularity algorithm and Louvain clustering required that the 2013 trade network first be converted to an undirected network. We also identified strongly connected components and cliques for the SMS in 2013.

Q: How have key sending and receiving systems and flow pathways changed over time?

We assessed the dynamics of relationships in the SMS over time using a variety of metrics; for each year from 1986 to 2013 we computed the density and connectedness of the entire network in addition to tracking the degree of each node and the temporal edge density of each node. We also calculated the duration of activity for nodes and edges between node pairs. In addition, we evaluated long-term community structure in the network, including all edges from all time steps to identify cliques and components. Because of the inconsistency of results from 2013, we did not execute the other community detection algorithms for the complete time series.

Q: Have past trade partnerships had a positive feedback on future trade partnerships?

We anticipated that countries with a higher number of trade partners in early years would increase trade partnerships more 
rapidly than countries starting with fewer trade partners, a case of positive feedback, in alignment with preferential attachment of nodes in networks (Newman 2001, Lü and Zhou 2011). A regression approach (e.g., Aknin et al. 2012) can be used to assess the existence of positive or negative feedbacks, and to test hypotheses regarding drivers. To examine feedbacks due to trade partnerships over time, we plotted the number of trade partners over time for each country that exported or imported soybean at least four times during the study period. We created linear models for trade for each of these countries relative to time and assessed whether the slopes of the linear models were significantly positive. We standardized the number of trade partners for each country over time by dividing the number of senders or receivers a particular country was connected to in a particular year by the total number of senders or receivers active across the entire SMS in that year.

\section{Q: To what extent have cross-scale dynamics from country to continent levels affected soybean trade patterns?}

To examine the level of interaction across spatial scales in the SMS, we fit exponential random graph models. This approach quantifies the probability of a given network, among all possible relationships between a given a set of nodes, and is conceptually similar to a generalized linear model approach (Holland and Leinhardt 1981, Morris et al. 2008). The ability of exponential random graph models to handle dependence of edges may make them better suited than gravity models for understanding geographic networks (Autant-Bernard and Hazir 2013). We tested whether a spatial hierarchy explained the observed soybean trade relationships between countries by quantifying connectivity within geographical regions, e.g., Eastern Africa, and continents, which were contained as attributes for each node.

Q: What spillover effects have emerging soybean sending systems had on the USA's role as an established dominant sending system? We tested the hypothesis that the USA was a spillover system, affected by emerging soybean sending countries; we used a series of simple and multiple regression models, in which emerging trade relationships between China and soybean sending countries, e.g., Brazil, Argentina, Canada, etc., were predictors for USA betweenness centrality. Our models were tests of hypotheses raised in previous research, given that emerging markets may affect established markets generally (International Monetary Fund 2011, Cullen and Mansur 2017, Dong et al. 2018, Li et al. 2018, Zhu et al. 2018). We tested a suite of models containing export data from South American and other countries that may affect the importance of the USA as a soybean trade hub (Gasparri et al. 2015, Sun et al. 2018). We particularly focused models on Brazil, because differences in the cost and timing of soybean production suggest that growth in Brazil soybean trade negatively affects the U.S. soybean trade (Flaskerud 2003). Moreover, the growth of soybean exports from middle-income countries is a driver of global trade (Hanson 2012).

Our goal was to explore whether the USA became a less important country in the sending system, i.e., decreased betweenness, because of increased competition from emerging markets. To determine which model best explained USA betweenness, we applied a model selection approach, using the size-corrected Akaike Information Criterion (AICc) to rank and weight the set of candidate models (Akaike 1974, Burnham and Anderson
2002). We then applied model averaging to determine modelweighted parameter estimates for the covariates across models in the candidate set, providing a general estimate of the importance of covariates in multiple models (Burnham and Anderson 2004).

Q: To what extent have ecological impacts, e.g., deforestation, occurred in tropical forests?

To demonstrate the use of network analysis to assess socialecological dynamics in the SMS, we quantified impacts on the tropical forest biome due to global soybean trade. We examined soybean flows in relation to deforestation detected from satellite imagery for soybean trading countries in the pantropics from 2000 to 2012. Specifically, we used linear regression to examine the relationship between the cumulative soybean export value and the cumulative sum of detected deforestation, as well as year-to-year differences in export value and deforested area for the 51 pantropical countries that exported soybean during the study period. We also examined whether there were any significant trends for the amount of deforestation occurring within distinct clearing size classes identified by Austin et al. (2017) and whether there were significant trends based on country income categories (low, lower middle, upper middle, or high income) at the start of the analysis period in 2000 . Forest loss data for each country were relativized by the estimated extent of forest at the start of the study period and then log (base 10) transformed.

\section{RESULTS}

Key soybean sending and receiving systems and flow pathways in 2013

Because Brazil (sending system), China (receiving system), and the USA (spillover system), have previously been identified as important nodes representing distinct parts of the SMS, we focused our results on these countries for demonstration purposes. Sending systems were generally concentrated in the western hemisphere in 2013, while receiving systems were located in the eastern hemisphere (Fig. 2A, B). In 2013, Brazil, Argentina, and the USA alone accounted for $80 \%$ of global soybean export value, highlighting their importance as soybean sending systems (Fig. 2A). China was the dominant soybean receiving system (Fig. 2B).

We found that relationships between countries in the SMS were weakly disassortative (Pearson $r=-0.085$ ) in 2013, indicating that hub countries with high degree values connected peripheral countries with low degree values. Brazil, China, and the USA represent some of the key hub nodes because they were involved in a disproportionate number of the total metacoupling interactions in 2013 and most other years (Fig. 3). The USA was involved in greater than average value soybean trades with 26 distinct partners, giving it the highest degree of these 3 countries of interest, followed by Brazil with 19, while China was involved in 6 partnerships where greater than average value of soybean trade occurred.

The existence of key flow pathways was revealed by identifying subnetwork structure within the SMS in 2013, in the form of communities, components, and cliques. Louvain clustering assigned nodes to 6 communities, with the largest community containing 66 nodes and a network modularity of 0.16 , indicating that the nodes within communities are slightly more related to one another than would be expected if they were randomly 
Fig. 2. Distribution of (A) soybean sending and (B) soybean receiving systems in the soybean metacoupled system, where countries were ranked in terms of export value (millions US\$) of soybean sent or received by each country.
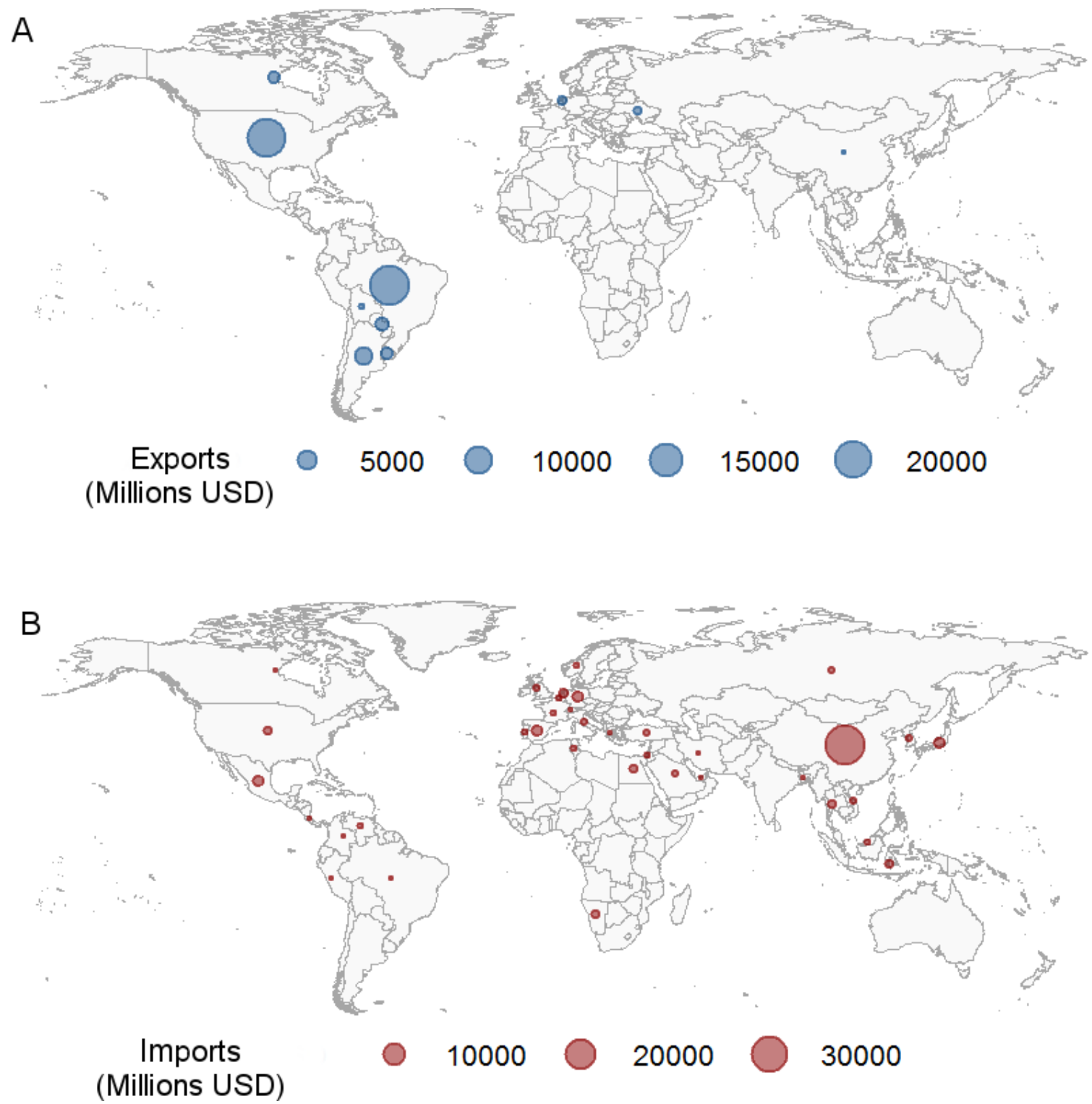

distributed (Table A2.1). The greedy algorithm identified 7 distinct communities, with the largest community containing 100 nodes, and a network modularity of 0.15 (Table A2.2). Louvain clustering and the greedy algorithm placed Brazil and China in the same community, while the USA was assigned to a separate community. The Newman-Girvan algorithm did not identify any distinct communities. We also identified 39 distinct components in 2013, with the largest connected component containing 3 countries. Clique assessment results considered 38 countries to be isolated, with 1 clique containing the USA and China, and a second clique consisting of the USA and Canada (Table A2.3, Appendix 3).

\section{Temporal dynamics}

We identified a clear trend of increasingly close relationships in the SMS from 1986 to 2013; a three-fold increase in network connectedness was observed (Fig. 4A) along with a five-fold increase in network density (Fig. 4B). Although the SMS has become more tightly connected, it has been characterized by volatile relationships. The set of countries engaged in soybean trade has not been consistent year to year; on average, a given node was active for $21.1 \%$ of the study period based on temporal edge density of the network. Among all possible trade pairings between soybean sending and receiving nodes, the likelihood that trade occurred between any pair of nodes in a given year was very low (temporal edge density $=0.012$ ). Furthermore, the average fraction of the total observed edges active at any time during the 
Fig. 3. Focal soybean metacoupled system countries' relationships in 2013: (A) Brazil's trade relationships, (B) China's trade relationships, (C) USA trade relationships. Countries are color coded based on whether they are net sending systems (blue), or net receiving systems (red) in each subnetwork. Arrows indicate the direction of soybean trade flows and the arrow width is weighted by the total export value (million US\$) of each transaction between trade partners. For illustration purposes, only countries that participated in greater than average annual transactions are shown. Although China also exports soybean, it is a net importer. Conversely, Brazil and the U. S. also import soybean, despite the fact that both are net exporters.

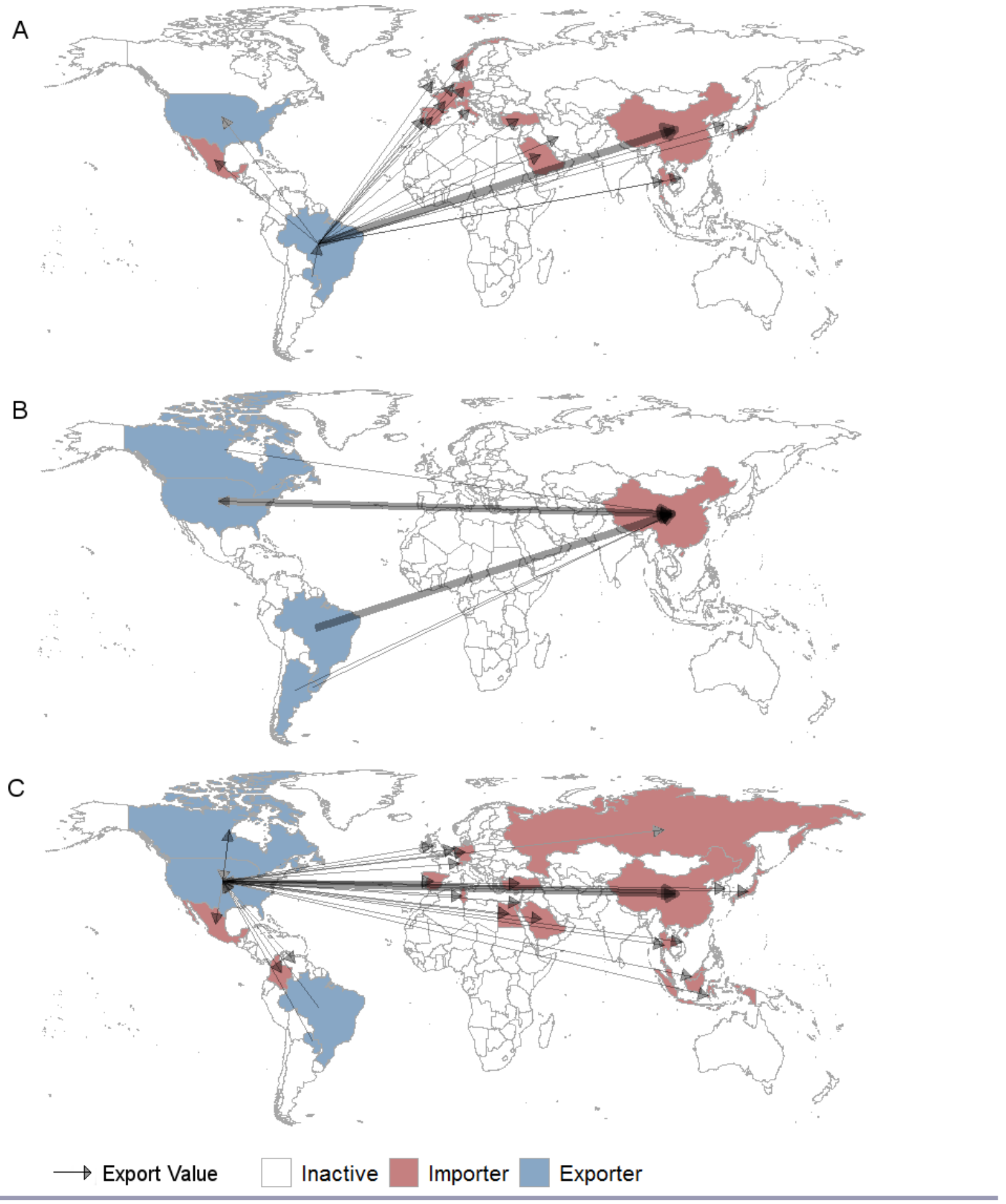


study period was 0.001 . A total of 2872 relationships existed in the network from 1986 to 2013 , yet just 1252 relationships $(\sim 52 \%)$ lasted for more than two years, 555 ties $(<20 \%)$ lasted at least 10 years, and only $47(<2 \%)$ lasted for the duration of the study period.

Fig. 4. Change in the connectivity of the soybean metacoupled system during 1986-2013: (A) network connectedness, or the fraction of all pairs of nodes where an undirected path exists, where 0 indicates an unconnected network and 1 indicates a completely connected network, (B) network density, or the portion of possible connections in a network that are actual connections.
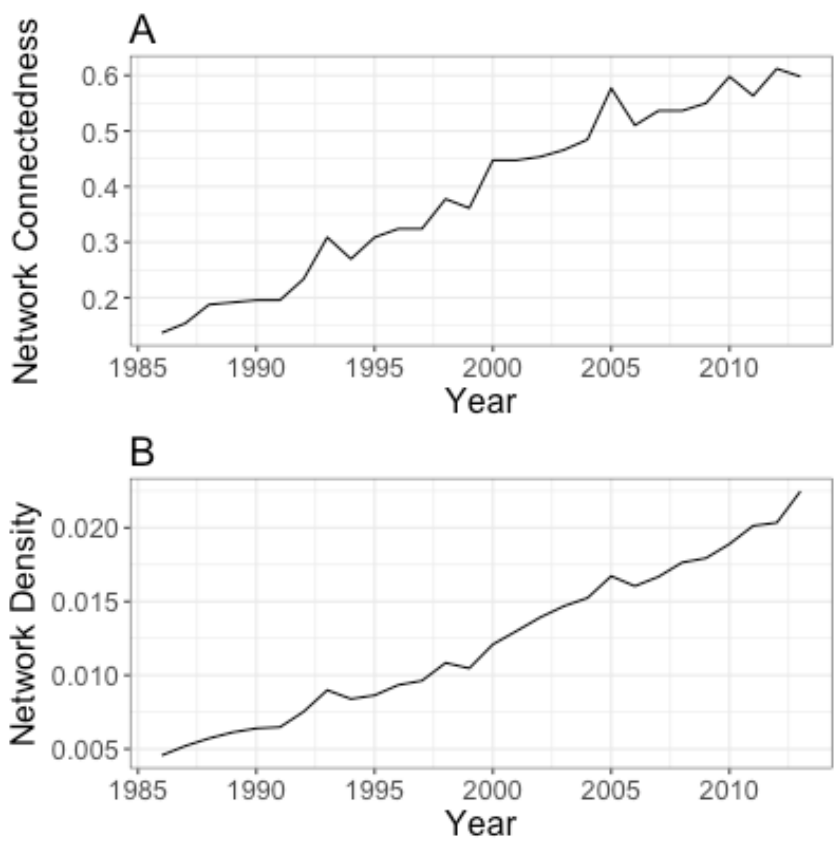

Despite the low probability of year-to-year trade activity across all nodes in the SMS, some nodes were extremely active. Out of a total of 2872 soybean flows transferred over the study period, Brazil was involved in 1078 (37.5\%), China featured in 1396 $(48.6 \%)$, and the USA was involved in 2077 (72.3\%). Although most countries did not have many long-term partnerships (Fig. $5 \mathrm{~A}$ ), those with a higher number of trading partners also tended to have more durable partnerships (Fig. 5B) as was the case for Brazil, China, and the USA. From 1986 to 2013, the majority of countries in the SMS were receivers, while only a few countries were responsible for sending the majority of soybean transferred to destination countries (Fig. 5C). Most prominent sending countries also received soybean.

Many key flow pathways were identified connecting subnetworks within the SMS when cliques across all years of data were considered. Though most of the 165 unique cliques detected had very few members, three cliques each contained six nodes (Table A2.4). Unsurprisingly, Brazil, China, and the USA frequently occurred in cliques. Brazil appeared in a total of five cliques (Table A2.4) with five distinct comembers, sharing membership in three cliques with Argentina (Appendix 4). China occurred in 11 cliques (Appendix 4) with 13 distinct comembers, led by the USA, which occurred in five cliques with China (Appendix 4). The USA was a part of 17 different cliques (Table A2.4), co-occurring with 20 other countries, most notably sharing five cliques with Canada and China, respectively (Appendix 4).

\section{Positive feedbacks due to soybean trade relationships}

We found evidence of a positive feedback with respect to the number of trading partners for a given country in the SMS over time, providing some support for preferential attachment of nodes. The slopes of linear models for raw counts of trade partners by country were significantly positive for China, Brazil, and USA at the $\alpha=0.05$ level (Table 1). Of the other countries that sent or received soybean for at least four years and had significant results, regression coefficients for the slope were positive for all but one of the 68 senders, and all but 8 of the 122 receivers (Appendix 5). However, when we converted counts to a proportion of total number of senders or receivers per year, the change over time was significantly negative for Brazil and USA, and nonsignificant for China. Slopes for linear models of trading partners as a proportion were negative for 17 of the 58 sending countries, and 45 of the 114 receiving countries. This suggests that the number of trade partners increased for all countries, not only those that began the time period with greater numbers of trade partners.

Fig. 5. Assessment of relationships across the soybean metacoupled system from 1986 to 2013: (A) histogram of durations of all trade partnerships in years for all countries, (B) degree centrality on the $y$-axis and total duration in years that each country has multiyear trade partnerships on the $\mathrm{x}$-axis, $(\mathrm{C})$ number of sending events relative to receiving events for each country.
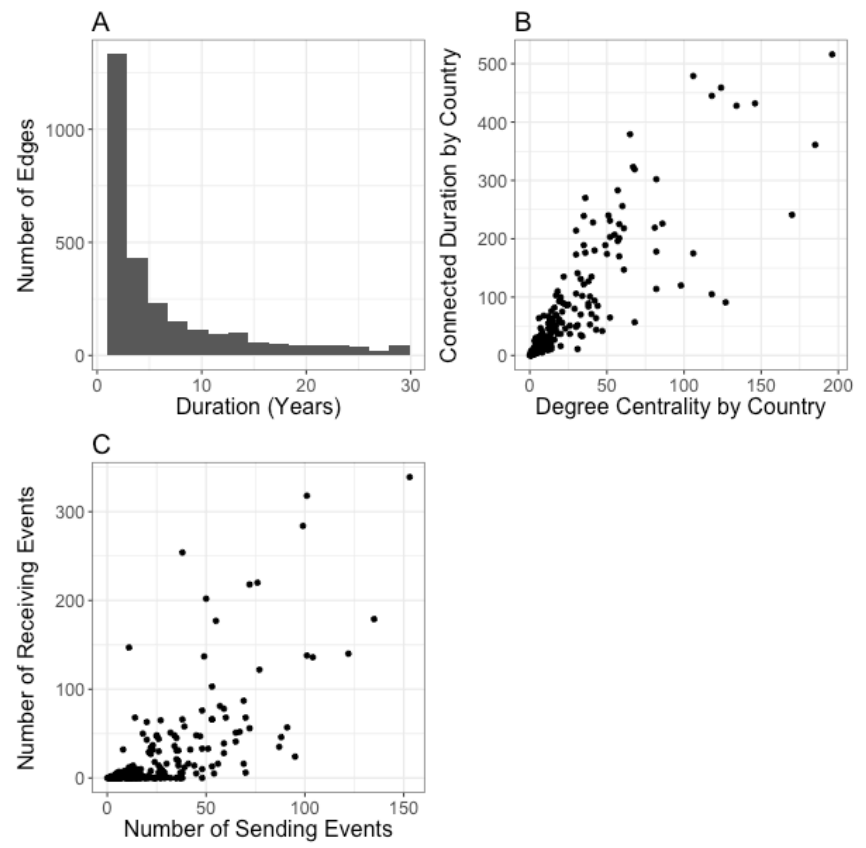

Cross-scale dynamics

Analysis of the soybean trade network with exponential random graph models indicated that the metacoupling relationships 
Table 1. Linear regressions of trade partnerships for key countries in terms of raw counts of sending (exporting) and receiving (importing) partners and proportions of total trade partners per year. The analysis was limited to countries that traded at least four times with another country for the period 1986-2013.

\begin{tabular}{|c|c|c|c|c|c|c|c|c|c|}
\hline & \multirow[t]{2}{*}{ Country } & \multirow{2}{*}{$\begin{array}{l}\text { Mean } \\
\text { proportion } \\
\text { of trade } \\
\text { partners }\end{array}$} & \multirow{2}{*}{$\begin{array}{l}\text { Number of } \\
\text { trade years }\end{array}$} & \multicolumn{3}{|c|}{ Counts } & \multicolumn{3}{|c|}{ Proportions } \\
\hline & & & & $\begin{array}{c}\text { Slope } \\
\text { Coefficient }\end{array}$ & $\begin{array}{c}\text { Slope } \\
\text { p-value }\end{array}$ & $\begin{array}{c}\text { Adjusted } \\
\text { Rsq }\end{array}$ & $\begin{array}{c}\text { Slope } \\
\text { Coefficient }\end{array}$ & $\begin{array}{c}\text { Slope } \\
\text { p-value }\end{array}$ & $\begin{array}{c}\text { Adjusted } \\
\text { Rsq }\end{array}$ \\
\hline \multirow[t]{5}{*}{ Senders } & USA & 0.11 & 28 & 0.7362 & 0.000 & 0.79 & -0.0057 & 0.000 & 0.82 \\
\hline & Brazil & 0.06 & 28 & 0.0361 & 0.022 & 0.15 & -0.0014 & 0.000 & 0.57 \\
\hline & China & 0.06 & 28 & 0.3049 & 0.000 & 0.73 & -0.0004 & 0.184 & 0.03 \\
\hline & Mean & 0.01 & 19 & 0.3349 & 0.007 & 0.44 & 0.0000 & 0.006 & 0.40 \\
\hline & Std Dev & 0.02 & 8 & 0.4469 & 0.013 & 0.24 & 0.0010 & 0.010 & 0.20 \\
\hline \multirow[t]{5}{*}{ Receivers } & USA & 0.03 & 28 & 0.7646 & 0.000 & 0.89 & -0.0004 & 0.002 & 0.30 \\
\hline & China & 0.02 & 28 & 0.1869 & 0.000 & 0.57 & 0.0000 & 0.823 & -0.04 \\
\hline & Brazil & 0.01 & 28 & 0.0747 & 0.000 & 0.46 & -0.0003 & 0.000 & 0.63 \\
\hline & Mean & 0.01 & 18 & 0.3524 & 0.006 & 0.46 & 0.0000 & 0.008 & 0.34 \\
\hline & Std Dev & 0.01 & 8 & 0.4473 & 0.011 & 0.25 & 0.0003 & 0.013 & 0.18 \\
\hline
\end{tabular}

observed could not be explained by regional $(\mathrm{p}=0.24)$ or continental groupings $(\mathrm{p}=0.20)$. Countries were not more likely to trade with their geographic neighbors in the same region or continent, but rather commonly traded outside of these geographical boundaries. Aggregation to regional and continental scales produced similar flow patterns to that observed when the network relationships were assessed between individual countries (Fig. 3). All regions and all continents in the SMS were both sending and receiving systems. Evaluating whether a node country, region, or continent was a net sender or receiver of soybean provided a way to identify the distribution of important sending and receiving systems at multiple scales.

\section{Economic spillovers among soybean sending countries}

Our model selection exercise indicated that major soybean sending countries in the southern hemisphere influenced the betweenness of the USA in the SMS (Table 2). The single best model to explain USA betweenness included the proportional value of all soybean sent to China from South American countries (Brazil, Argentina, Uruguay, and Paraguay), with an AICc weight $\left(w_{i}\right)$ of $0.53\left(\operatorname{adj} . \mathrm{r}^{2}=0.65, \mathrm{p}<0.01\right)$. Other models that performed well included the proportional value of soybean sent to China from Brazil as a covariate, most notably those models that included soybean sent from Brazil, Argentina, and South Africa $\left(w_{i}=0.23\right.$, adj. $\left.\mathrm{r}^{2}=0.67, \mathrm{p}<0.01\right)$ and Brazil and Argentina $\left(w_{i}\right.$ $=0.14$, adj. $\left.\mathrm{r}^{2}=0.64, \mathrm{p}<0.01\right)$. Poorly performing models $(\triangle \mathrm{AICc}$ $\left.>10, w_{i}<0.01\right)$ included the model considering soybean sent to China from Argentina alone, and models including the proportional value of soybean from the top 10 senders to China, both collectively and for each of these sending countries as individual covariates. The worst model, as ranked by AICc, was the full model that included all covariates; this model ranked worse than even the intercept-only model.

Model averaging indicated that South American exports of soybean to China positively influenced USA betweenness, as measured by model averaged regression coefficients of the value of soybean sent to China (Table 3). The sum of all South American countries that sent soybean to China (Brazil, Argentina, Uruguay, and Paraguay) had the strongest positive influence on USA betweenness $(\beta=684.6, \mathrm{SE}=100.7, \mathrm{p}<0.01)$. The model averaged parameter for models of soybean sent from Brazil to China was 430.1 ( $\mathrm{SE}=171.4, \mathrm{p}=0.01)$ and for soybean sent from Argentina to China was $319.7(\mathrm{SE}=134.5, \mathrm{p}=0.02)$. The sum of soybean exports to China from all countries except USA, Brazil, and Argentina indicated negative effects on USA betweenness, with a model averaged parameter of -627.6 (SE = 115.3, $\mathrm{p}<0.01)$; however, model selection indicated that this was a low-ranked model ( $w_{i}=0.01$, adj. $\left.\mathrm{r}^{2}=0.54, \mathrm{p}<0.01\right)$, so the sum of these countries' influence is minor. Model averaged parameters for covariates representing proportional trade from each other individual country included in other models had $\mathrm{p}>0.05$.

\section{Ecological impacts on tropical forests 2000-2012}

For pantropical countries that exported soybean from 2000 to 2012, we found that cumulative deforestation was significantly associated with the cumulative value of soybean flows exported by country, when both measures were relativized by forest cover in 2000 (Fig. 6, Fig. A6.1-A6.3, $\mathrm{r}^{2}=0.35, \mathrm{p}<0.0001$ ). Soybean exports were a more important driver of deforestation over the study period for countries lying closer to the regression line, e.g., Paraguay, whereas soybean exports alone did not adequately explain observed deforestation over the study period for countries further from the regression line, e.g., South Africa. Significant trends were identified within the low income $\left(r^{2}=0.42, p=0.001\right)$, lower-middle $\left(\mathrm{r}^{2}=0.65, \mathrm{p}<0.0001\right)$, and upper-middle income countries $\left(r^{2}=0.51, p=0.03\right)$, but not for high-income countries. No significant trends were identified for deforested clearing size classes. The year-to-year difference in soybean export flows was also a significant, but weak, predictor of the difference in deforested area by country over the study period when both measures were relativized by forest cover in $2000\left(\mathrm{r}^{2}=0.07, \mathrm{p}=\right.$ 0.007).

\section{DISCUSSION}

Using the SMS as an example, we demonstrated that network analysis is a powerful and flexible tool for integrating socioeconomic and ecological data to understand spatiotemporal and cross-scale dynamics of metacoupled systems, including flows, feedbacks, and spillover effects. Our integration of the widely used tool of network analysis shows a path forward to quantify the distinct dynamics of metacoupled systems. 
Table 2. Results of model selection indicate how the USA's betweenness, as an established soybean sending system, was affected by the value of soybean exported to China from other major sending countries. Models refers to the covariates for each of the models; $\mathrm{K}$ indicates the number of parameters in each model; AICc is the size-corrected Akaike Information Criterion (AICc; Akaike 1973, Burnham and Anderson 2002) that was used to rank models; $\triangle \mathrm{AICc}$ is the difference between each model and the top model; w is the AICc weight of each model.

\begin{tabular}{|c|c|c|c|c|}
\hline Models & $\mathrm{K}$ & $\mathrm{AICc}$ & $\triangle \mathrm{AICc}$ & $\mathrm{w}$ \\
\hline Sum of Brazil, Argentina, Uruguay, Paraguay & 3 & 432.25 & 0.00 & 0.53 \\
\hline Brazil + Argentina + South Africa & 5 & 433.92 & 1.67 & 0.23 \\
\hline Brazil + Argentina & 4 & 434.83 & 2.59 & 0.15 \\
\hline Brazil & 3 & 437.38 & 5.14 & 0.04 \\
\hline Brazil + Argentina + Uruguay + Paraguay & 6 & 437.45 & 5.20 & 0.04 \\
\hline Sum of all countries except Brazil, Argentina, and USA & 3 & 439.86 & 7.62 & 0.01 \\
\hline Argentina & 3 & 447.32 & 15.08 & 0.00 \\
\hline $\begin{array}{l}\text { Brazil }+ \text { Argentina }+ \text { Uruguay }+ \text { Paraguay }+ \text { Canada }+ \text { Russia }+ \text { Australia }+ \text { South Africa }+ \text { India } \\
+ \text { Ethiopia (Top } 10 \text { exporters to China) }\end{array}$ & 12 & 452.30 & 20.05 & 0.00 \\
\hline $\begin{array}{l}\text { Sum of Brazil, Argentina, Uruguay, Paraguay, Canada, Russia, Australia, South Africa, India, } \\
\text { Ethiopia (Top } 10 \text { exporters to China) }\end{array}$ & 3 & 455.91 & 23.67 & 0.00 \\
\hline Intercept only & 2 & 460.09 & 27.85 & 0.00 \\
\hline Full model & 15 & 467.94 & 35.69 & 0.00 \\
\hline
\end{tabular}

Fig. 6. Linear regression of cumulative annual forest loss and cumulative soybean export value for pantropical countries (2000-2012). The cumulative sum of detected forest loss (Hansen et al. 2013; Fig A6.2) and soybean export value (Department of Economic and Social Affairs Statistics Division 2010, Food and Agriculture Organization of the United Nations 2016; Fig A6.3) by country were both normalized by the extent of forest with $>50 \%$ tree cover at the start of the period in the year 2000 (Fig. A6.1) and log (base 10) transformed.

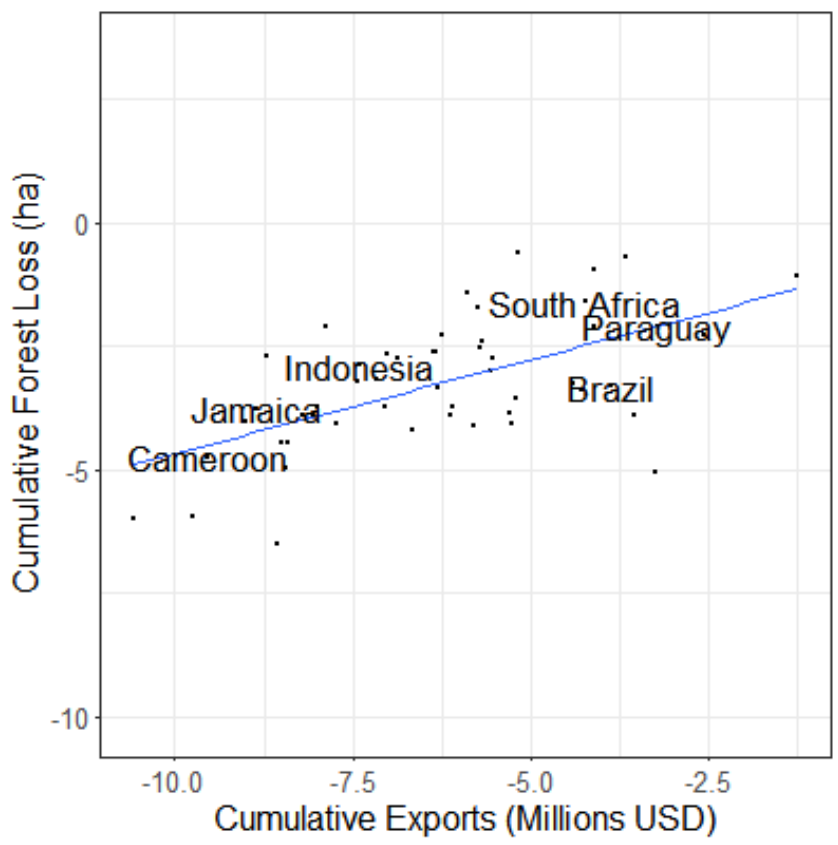

Key sending and receiving systems and flow pathways

Network analysis provided a quantitative approach to identify the key sending and receiving systems and flow pathways in the SMS in 2013. The significant emphasis of previous studies on the USA, China, and Brazil is justified given their involvement in a large share of the flows in the SMS. We also found evidence that groups of soybean trading countries were more connected to each other than to the broader SMS. However, community identification was not consistent across methods; for example, modularity-based methods placed Brazil and China in a community separate from the USA, while clique-based methods placed the USA and China in a clique and considered Brazil to be an isolated node. To improve confidence in tracking hierarchical structure and key flow pathways in metacoupled systems over time, future work could test the robustness of partitions that define communities (e.g., Fortunato 2010). Examining the attributes of community member nodes, and network assortativity, in greater detail may also provide insight into the basis of these communities and their role in metacoupled systems. Metacoupled systems that incorporate social, economic and ecological aspects may not fit the expectations of assortativity in the literature for networks that focus on just one of these dimensions (Newman 2003). Better understanding these aspects of network structure may aid in understanding potential food security risks because other researchers have found community configuration affects supply chain stability (e.g., Acemoglu et al. 2012).

Despite the east-west divide separating soybean senders and receivers, many dominant senders also received soybean. These transactions could be explained by specialized markets, i.e., organic soy milk and tofu for human consumption (Sun et al. 2015). Alternatively, this could be explained by changing marginal costs for cultivation of soybean and transportation of the product to reach consumers. For example, transport by rail or boat could be a factor in trades depending on whether the ultimate destination of the product is located in the USA interior as opposed to the coasts (Clott et al. 2015). It may be informative to further explore the relative importance of edges with distinct 
Table 3. Model averaged regression coefficients and associated statistics derived from the model set in the model selection exercise to assess spillover in the soybean metacoupled system. Covariate indicates covariates from models; Estimate indicates the model averaged regression coefficients; Adjusted SE is the adjusted standard error (Burnham and Anderson 2002); $\mathrm{z}$ value is the test statistic for the test; and $\mathrm{p}$ value is the $\mathrm{p}$ value associated with the test statistic.

\begin{tabular}{|c|c|c|c|c|}
\hline Covariate & Estimate & Adjusted SE & z value & $\mathrm{p}$ value \\
\hline (Intercept) & 2543.7 & 99.1 & 25.68 & 0.00 \\
\hline Sum of Brazil, Argentina, Uruguay, and Paraguay & 684.6 & 100.7 & 6.80 & 0.00 \\
\hline Brazil & 430.1 & 171.4 & 2.51 & 0.01 \\
\hline $\begin{array}{l}\text { Sum of Brazil, Argentina, Uruguay, Paraguay, Canada, Russia, Australia, South Africa, } \\
\text { India, Ethiopia }\end{array}$ & 387.5 & 154.0 & 2.52 & 0.01 \\
\hline Argentina & 319.7 & 134.5 & 2.38 & 0.02 \\
\hline South Africa & 222.3 & 123.6 & 1.80 & 0.07 \\
\hline Paraguay & 161.0 & 107.0 & 1.51 & 0.13 \\
\hline Ethiopia & 20.1 & 124.9 & 0.16 & 0.87 \\
\hline India & -45.9 & 112.5 & 0.41 & 0.68 \\
\hline Uruguay & -47.5 & 116.3 & 0.41 & 0.68 \\
\hline Australia & -68.8 & 163.4 & 0.42 & 0.67 \\
\hline Canada & -70.7 & 204.2 & 0.35 & 0.73 \\
\hline Russia & -111.1 & 133.3 & 0.83 & 0.40 \\
\hline Sum of all countries except USA, Brazil, and Argentina & -627.6 & 115.3 & 5.44 & 0.00 \\
\hline
\end{tabular}

attributes; for example, Zhu et al. (2014) found that bidirectional edges were more important to diffusion within online social networks than edges that only operated in one direction. Analysis using soybean trade data provides partial understanding of supply and demand factors, but a comprehensive assessment would require actual soybean production and consumption data, ideally at a subnational scale.

\section{Temporal trends, feedbacks, and lag effects}

Not only did the SMS become more connected over time, but we also identified evidence of a positive feedback in the number of intercoupling relationships by country over time. The increasingly smaller set of dominant trade partnerships that has emerged has implications for food security. Because very few countries comprise the soybean sending system, policy changes or natural disasters in these locations could cause significant disruptions in the SMS. Brazil and the USA both cultivate large swaths of land with monocultural GM varieties of soybean (HighQuest Partners and Soyatech 2011), which could be particularly vulnerable to drought or disease.

Social, economic, and political legacies may be at play in the trade patterns observed; countries that traded with more partners had longer lasting intercoupling relationships. On the other hand, market perturbations due to changes in supply and demand may explain some of the other metacoupling dynamics. An increase in the value of exports from Brazil and the USA to China began around 2000 and a steep increase was observed in 2007. In addition to these demand-side factors, another explanation for this spike may be a lag response to USA energy policies. Driven by policies incentivizing corn production for biofuels, USA soybean cultivation dropped beginning in 2004-2005, sending both soybean and corn prices soaring (HighQuest Partners and Soyatech 2011). There may have been a lag effect before this impact was felt globally, after existing harvested supplies were depleted. Lag effects may also complicate detection of associations between soybean trade and deforestation. Soybean cultivation is often associated with preceding deforestation for grazing areas, which are later converted into soybean production (Rudel et al. 2009, Graesser et al. 2015). When assessing how deforestation is related to subsequent soybean export observations, it may be important to account for the time required to clear land and achieve a successful crop that can be brought to market.

\section{Cross-scale dynamics}

Our analysis revealed extreme globalization in the SMS; geography had no bearing on the relationships between countries, but rather telecoupling interactions across long distances dominated the trade patterns we observed. We also found that soybean exports to spatially distant countries in the SMS were associated with spatially concentrated tropical forest loss patterns, which have been well quantified in previous work (Rudel et al. 2009), but not formally evaluated in a metacoupled systems context. Our findings highlight a potential limitation of neighborhood analyses commonly used in ecological studies, where observations that are closer in space or time are expected to be more closely related; metacoupled systems may not fit these classic conceptualizations of natural systems, and offer exciting opportunities to push theoretical boundaries. It is also worth noting that most metacoupled systems research has assumed that long-distance relationships are the most important to consider, but has not quantified the relative importance of pericoupling relationships between spatially nearby systems and telecoupling interactions over distances, as we have demonstrated here using exponential random graph models. We suggest that this would be a useful step for exploratory data analysis in future studies.

\section{Spillover effects}

Previous network analysis-based studies have typically ignored or omitted consideration of spillovers. Using a metacoupling approach necessitates the need to consider this entirely new type of connection, and it can provide novel cases not previously explored using network analysis techniques. Although we expected that the emergence of Brazil and Argentina as growing major soybean senders to China would diminish the importance 
of the USA as a key soybean trade hub, we were surprised to find strong evidence that increases in exports from emerging South American sending countries were associated with an increase with USA betweenness. Increased demand for soybean over time may explain these observations. Degree centrality increased for the major soybean sending countries over the study period, which was probably accommodated by strong and increasing demand from China.

We demonstrated proof of concept that a model selection approach can be used to identify and quantify spillovers in metacoupled systems as measured by changes in network analysis metrics. Using the model selection framework allowed direct comparison of the predictive value of potential drivers of network metrics. Including additive terms in models enabled assessment of cross-scale differences, and comparison across regions. Moreover, model averaging permitted general conclusions about the role of particular agents in metacoupled systems. Future studies could use community detection results to guide the choice of candidate models. Additional influences on USA betweenness could be considered by testing other models. For example, demand for biofuel and other land uses could drive soybean production patterns, which cannot be captured by soybean trade data alone. We also expect that seasonal, or even finer temporal resolution trade data would provide more evidence of spillover effects due to competition between soybean sending countries, rather than only annual data. However, we do not expect such dynamics would be as clearly observed for soybean as for perishable products such as fruits and vegetables. We examined betweenness as one metric of the importance or influence of the USA in the soybean market, but we also note that other network indicators could also be analyzed in similar ways. Alternative metrics could provide additional insight into network relationships, or perhaps a composite index of multiple network metrics could summarize these relationships. Future studies should select among the many network metric options to target those most relevant for specific research questions or hypotheses.

\section{Social-ecological linkages}

The ability to include social and ecological datasets as either node or edge attributes, or as the links between nodes, makes network analysis uniquely suited for assessing interactions between these distinct dimensions of metacoupled systems. We demonstrated that it is possible to quantify ecological impacts on tropical forests because of the soybean metacoupled system. Our results highlighting the linkage between soybean exports and deforestation over the period 2000-2012 corroborate other studies that have found that export-oriented agriculture is an important driver of tropical deforestation (e.g., DeFries et al. 2010, Austin et al. 2017). We expect that stronger associations would be found if subnational soybean production and trade data were available to permit quantification of intracoupling in the soybean metacoupled system. Additionally, deforestation patterns would likely be better explained by assessing multiple commercial crops to understand the suite of specific drivers operating in different regions. For example, oil palm cultivation has emerged as a prominent driver of deforestation, particularly in Southeast Asia, driven by demand in distant locations (Fitzherbert et al. 2008). Finally, other drivers unrelated to agriculture could also be responsible for detected deforestation.
Deforestation occurring in soybean exporting countries in the pantropics could also be assessed as a spillover system. These spillover effects in nearby and distant countries could be further explored in future work. Incorporating either coarser regional, or finer scale subnational soybean trade and deforestation data would allow us to quantify ecological spillover effects due to the SMS.

\section{Quantitative analysis methods and data access for metacoupled} systems research

Our understanding of the SMS and other metacoupled systems can be enhanced through quantitative approaches, including, but not limited to network analysis. Transdisciplinary partnerships among landscape ecologists, economists, climatologists, sociologists, and other specialists can help develop a contextually deep understanding of the diverse dimensions of metacoupled systems. For example, gravity models have been widely used in previous trade studies, in which the flows of goods are conditioned on the level of economic activity at each location (e.g., Anderson 2011, Tamea et al. 2014, Fracasso 2014, Tuninetti et al. 2017). In addition, we suggest that structural equation modelling (Grace 2006, Kline 2011) and agent-based modeling methods (Ford 2010) would be useful, particularly for quantifying effects in spillover systems and analyzing nonlinear feedbacks. Agent-based modeling involving process-based simulations could be useful for evaluating the probability space for deforestation outcomes given decisions and interactions at more regional and local scales (An et al. 2005, Liu et al. 2015c). The recently developed telecoupling toolbox (Tonini and Liu 2017) also offers a promising option to assist researchers in linking diverse datasets related to human and natural systems and conducting spatially explicit analysis within a GIS environment.

Future work on the SMS using other quantitative methods could further test hypotheses against alternatives, and more explicitly assess causality. For example, one hypothesis we suggest is that regional and international trade agreements may explain the important flow pathways connecting the cliques and components that we identified. The availability of undeveloped land, access to rail and boat transport networks, and access to global markets could also be important considerations. Although we did not examine cross-scale interactions in time, we would expect that the market price of soybean, as well as changing costs of production and the cost of alternatives to soybean also influence the SMS.

Despite the clear utility of network analysis for understanding the SMS and other metacoupled systems, data scarcity and lack of data access from centralized repositories continue to present major challenges to implementing a full-scale quantitative analysis of metacoupled systems. Additional assessments are needed that bring together long-term social and ecological patterns at multiple scales to examine interactions, feedbacks, and spillover effects that may play out at different rates and across hierarchical levels within metacoupled systems. Only rich datasets will permit a robust test of the full potential of the metacoupling framework to add predictive power over traditional analysis approaches. 


\section{CONCLUSION}

We have demonstrated using freely available datasets that network analysis provides a flexible method to study metacoupled systems, such as the SMS, by linking dynamic socioeconomic changes, i. e., in soybean trade patterns, with biophysical changes on the landscape, i.e., deforestation. Network analysis can be applied more broadly in order to better understand the nature of metacoupled systems globally. Given appropriate data, network analysis techniques can assist in identifying distributions of sending, receiving, and spillover systems, tracking the structure and strength of connections among systems across scales. Network analysis approaches can be used to assess cross-scale dynamics, including identifying feedbacks that may manifest as causes and effects at different spatial and temporal scales. Such work may provide additional insights into the processes responsible for forming, reinforcing, or weakening connections in metacoupled systems. In turn, metacoupled systems offer novel opportunities to test and advance network theory for which expectations are typically defined based on well-established characteristics of social or ecological networks individually, rather than simultaneously considering these aspects. Using the metacoupling framework also requires consideration of linkages not previously represented in network analysis studies, particularly connections to spillover systems. Using available quantitative tools and expertise across various disciplines to quantify metacoupled systems can help us to better understand what gives rise to metacouplings, how they evolve in time and space, and what positive and negative effects they may produce. Understanding these systems will be key to developing appropriate policies to avoid and mitigate potentially undesirable trade-offs, and to more sustainably manage global resources for the future.

\section{Box 1: Network Analysis}

Network analysis, an application of graph theory (Urban and Keitt 2001, Fortin et al. 2012), is a versatile approach that can be used to describe how different components of social and ecological systems are connected (Minor and Lookingbill 2010, Penuel et al. 2012). A network consists of a set of nodes, which are connected by edges representing the flows or interactions among nodes (Urban and Keitt 2001, Fortin et al. 2012). Various metrics can describe the degree to which the network facilitates or impedes the flow of organisms and materials (Taylor et al. 1993) or connectivity among social agents (Borgatti et al. 2009). Network analysis is flexible to inclusion of spatial and aspatial data, continuous and nominal attributes, and both anthropogenic and natural flows that may be of interest for complex metacoupled systems. Here we define key network analysis terminology and metrics used to analyze the soybean metacoupled system in this study.

Terminology (Wasserman and Faust 1994, Girvan and Newman 2002, Newman 2004)

Adjacent: The condition when two different nodes (countries) are connected by an edge (soybean trade occurs between them).

Assortativity: Describes the pattern of how nodes in a network are connected to each other. The assortativity coefficient is the Pearson correlation coefficient $r$; where $r>0$ indicates an assortative network, $\mathrm{r}<0$ indicates a disassortative network, and $r=0$ is an uncorrelated network (Newman 2003).

Assortative: Describes a network in which nodes with similar attributes, e.g., degree or spatial location, preferentially connect to one another.

Betweenness: A metric summarizing the number of connected pathways among nodes that go through a given node; greater betweenness means that a node is more frequently a step in the relationships that connect another two nodes.

Clique: A subnetwork in which every two distinct nodes are adjacent.

Component: A subnetwork in which any two nodes are connected, and which is connected to no additional nodes in the broader network. An isolated node with no edges can also be considered a component.

Community: A tightly connected cluster of nodes within a network.

Connectedness: Here, we defined connectedness as the Krackhardt connectedness score (Krackhardt 1994). This is comprised of the fraction of all pairs of nodes where an undirected path exists. The Krackhardt connectedness score ranges from 0 to 1 , with 1 being a completely connected network.

Degree: The number of direct connections a node has.

Density: The portion of potential connections in a network that are actual connections.

Destination: A node that is receiving (importing) soybean from another node.

Directed: Describes a network where the edges have a direction associated with them.

Disassortative: Describes a network in which more isolated nodes are linked into the broader network through highly connected hub nodes.

Duration: Event counts or duration of connectivity between nodes. Here, we measure duration in years.

Edge: A connection or link between nodes. Here, edges are soybean trade relationships.

Modularity: The fraction of edges that fall within communities minus the expected fraction if edges were distributed at random. The value of modularity lies in the range $[-1 / 2,1]$. It is positive if the number of edges within communities exceeds the number expected on the basis of chance.

Network (Graph): A mathematical structure of nodes connected by edges, used to understand pairwise relationships.

Node: Entities connected by edges in a network, also called a vertex. Here, nodes represent soybean sending (exporting) and receiving (importing) countries.

Origin: A node that is sending (exporting) soybean to another node.

Subnetwork: A subset of a network, also known as a neighborhood or community. 
Responses to this article can be read online at: http://www.ecologyandsociety.org/issues/responses. $\mathrm{php} / 10460$

\section{Acknowledgments:}

DS was supported by a NASA Earth and Space Science Fellowship (NNX13AQ15H) and a P.E.O. Scholar Award. SAT was funded by the Canadian Network for Aquatic Ecosystem Services and the Holdsworth Foundation. KJJ was supported in part by the U.S. Department of Defense through the Strategic Environmental Research and Development Program (SERDP; project RC-1722). DYM was supported by a USDA-ARS Area Wide Project Grant. MLT was partially supported by the NSF-EPSCoR Program (OIA-1301789). JL was supported by U.S. National Science Foundation and Michigan AgBioResearch. This research built on initial discussions among a group of junior researchers at the 2014 Annual Meeting of the US Regional Association of the International Association for Landscape Ecology, which also included Marufa Akther, Caroline Curtis, Whalen Dillon, Lisa Green, Binbin Li, Alexis Maldonado, Katherine Renwick, Eric Taber, Hui Xu, Hongbo Yang. Funding to support attendance at the US-IALE meeting was provided by the NASA-MSU Professional Enhancement Awards Program. We thank Amanda Schwantes and four anonymous reviewers for providing thoughtful comments, which greatly improved the quality of the manuscript.

\section{LITERATURE CITED}

Acemoglu, D., V. M. Carvalho, A. Ozdaglar, and A. TahbazSalehi. 2012. The network origins of aggregate fluctuations. Econometrica 80(5):1977-2016. http://dx.doi.org/10.3982/ECTA9623

Akaike, H. 1974. A new look at the statistical model identification IEEE Transactions on Automatic Control 19(6):716-723.

Aknin, L. B., E. W. Dunn, and M. I. Norton. 2012. Happiness runs in a circular motion: evidence for a positive feedback loop between prosocial spending and happiness. Journal of Happiness Studies 13(2):347-355. http://dx.doi.org/10.1007/s10902-011-9267-5

Aldasoro, I., and I. Angeloni. 2013. Input-output-based measures of systemic importance. SAFE Working Paper Series No. 29. Universität Frankfurt a. M., Frankfurt am Main, Germany. http://dx.doi.org/10.2139/ssrn.2317299

An, L., M. Linderman, J. Qi, A. Shortridge, and J. Liu 2005 Exploring complexity in a human-environment system: an agentbased spatial model for multidisciplinary and multiscale integration. Annals of the Association of American Geographers 95:54-79. http://dx.doi.org/10.1111/j.1467-8306.2005.00450.x

Anderson, J. E. 2011. The gravity model. Annual Review of Economics 3(1):133-160. $\underline{\text { http://dx.doi.org/10.1146/annurev- }}$ economics-111809-125114

Arel-Bundock, V. 2014. countrycode: Convert country names and country codes.

Asner, G. P., G. V. N. Powell, J. Mascaro, D. E. Knapp, J. K. Clark, J. Jacobson, T. Kennedy-Bowdoin, A. Balaji, G. Paez-Acosta, E. Victoria, L. Secada, M. Valqui, and R. F. Hughes. 2010. Highresolution forest carbon stocks and emissions in the Amazon.
Proceedings of the National Academy of Sciences of the United States of America 107(38):16738-16742. http://dx.doi.org/10.1073/ pnas. 1004875107

Austin, K. G., M. González-Roglich, D. Schaffer-Smith, A. M. Schwantes, and J. J. Swenson. 2017. Trends in size of tropical deforestation events signal increasing dominance of industrialscale drivers. Environmental Research Letters 12(5). http://dx.doi. org/10.1088/1748-9326/aa6a88

Autant-Bernard, C., and Ç. S. Hazir. 2013. Network formation and geography: modelling approaches, underlying conceptions, recent and promising extensions. Pages 15-28 in T. Scherngell, editor. The Geography of Networks and $R \& D$ Collaborations. Springer, Cham, Switzerland. http://dx.doi.org/10.1007/978-3-319-02699-2 2

Barrat, A., M. Barthélemy, and A. Vespignani. 2008. Dynamical processes on complex networks. Cambridge University Press, Cambridge, UK. http://dx.doi.org/10.1017/CBO9780511791383

Bartoń, K. 2018. MuMIn: R package for model selection and multi-model inference. [online] URL: http://mumin.r-forge.rproject.org/

Bender-deMoll, S., and M. Morris. 2016. tsna: Tools for temporal social network analysis.

Blondel, V. D., J.-L. Guillaume, R. Lambiotte, and E. Lefebvre. 2008. Fast unfolding of communities in large networks. Journal of Statistical Mechanics: Theory and Experiment (10):P10008. http://dx.doi.org/10.1088/1742-5468/2008/10/P10008

Blonder, B., T. W. Wey, A. Dornhaus, R. James, and A. Sih. 2012. Temporal dynamics and network analysis. Methods in Ecology and Evolution 3(6):958-972. http://dx.doi.org/10.1111/ j.2041-210X.2012.00236.X

Bodin, Ö., and B. I. Crona. 2009. The role of social networks in natural resource governance: What relational patterns make a difference? Global Environmental Change 19(3):366-374. http:// dx.doi.org/10.1016/j.gloenvcha.2009.05.002

Borgatti, S. P., A. Mehra, D. J. Brass, and G. Labianca. 2009. Network analysis in the social sciences. Science 323 (5916):892-895. http://dx.doi.org/10.1126/science.1165821

Bui-Klimke, T. R., H. Guclu, T. W. Kensler, J.-M. Yuan, and F. Wu. 2014. Aflatoxin regulations and global pistachio trade: insights from social network analysis. PLOS ONE 9(3):e92149. http://dx.doi.org/10.1371/journal.pone.0092149

Burnham, K. P., and D. R. Anderson. 2002. Model selection and multimodel inference: a practical information-theoretic approach. Second edition. Springer-Verlag, New York, New York, USA. http://dx.doi.org/10.1007/b97636

Burnham, K. P., and R. P. Anderson. 2004. Multimodel inference: understanding AIC and BIC in model selection. Sociological Methods \& Research 33(2):261-304. http://dx.doi. org/10.1177/0049124104268644

Butts, C. T. 2008a. network: A package for managing relational data in R. Journal of Statistical Software 24(2). http://dx.doi. org/10.18637/jss.v024.102

Butts, C. T. 2008b. Social network analysis with sna. Journal of Statistical Software 24(6). http://dx.doi.org/10.18637/jss.v024. $\underline{\mathrm{i} 06}$ 
Butts, C. T., A. Leslie-Cook, P. N. Krivitsky, and S. BenderdeMoll. 2016. networkDynamic: Dynamic extensions for network objects.

Cai, H., and Y. Song. 2016. The state's position in international agricultural commodity trade: a complex network. China Agricultural Economic Review 8(3):430-442. http://dx.doi. org/10.1108/CAER-02-2016-0032

Carlson, A. K., W. W. Taylor, J. Liu, and I. Orlic. 2017. The telecoupling framework: an integrative tool for enhancing fisheries management. Fisheries 42(8):395-397. http://dx.doi. org/10.1080/03632415.2017.1342491

Carter, N. H., A. Viña, V. Hull, W. J. McConnell, W. Axinn, D. Ghimire, and J. Liu. 2014. Coupled human and natural systems approach to wildlife research and conservation. Ecology and Society 19(3):43. http://dx.doi.org/10.5751/ES-06881-190343

Carvalho, H., A. P. Barroso, V. H. Machado, S. Azevedo, and V. Cruz-Machado. 2012. Supply chain redesign for resilience using simulation. Computers and Industrial Engineering 62(1):329-341. http://dx.doi.org/10.1016/j.cie.2011.10.003

Cash, D. W., W. Adger, F. Berkes, P. Garden, L. Lebel, P. Olsson, L. Pritchard, and O. Young. 2006. Scale and cross-scale dynamics: governance and information in a multilevel world. Ecology and Society 11(2):8. http://dx.doi.org/10.5751/ES-01759-110208

Clauset, A., M. E. J. Newman, and C. Moore. 2004. Finding community structure in very large networks. Physical Review E 70(066111). http://dx.doi.org/10.1103/PhysRevE.70.066111

Clott, C., B. C. Hartman, E. Ogard, and A. Gatto. 2015. Container repositioning and agricultural commodities: shipping soybeans by container from US hinterland to overseas markets. Research in Transportation Business \& Management 14:56-65. http://dx.doi. org/10.1016/j.rtbm.2014.10.006

Contreras, M. G. A., and G. Fagiolo. 2014. Propagation of economic shocks in input-output networks: a cross-country analysis. Physical Review E 90(6):062812. http://dx.doi. org/10.1103/PhysRevE.90.062812

Csardi, G., and T. Nepusz. 2006. The igraph software package for complex network research. InterJournal, Complex Systems 1695 (5):1-9.

Cullen, J. A., and E. T. Mansur. 2017. Inferring carbon abatement costs in electricity markets: a revealed preference approach using the shale revolution. American Economic Journal: Economic Policy 9(3):106-133. http://dx.doi.org/10.1257/pol.20150388

Dalin, C., M. Konar, N. Hanasaki, A. Rinaldo, and I. RodriguezIturbe. 2011. Evolution of the global virtual water trade network. Proceedings of the National Academy of Sciences 2011:1-6.

Davis, K. F., P. D'Odorico, F. Laio, and L. Ridolfi. 2013. Global spatio-temporal patterns in human migration: a complex network perspective. PLOS ONE 8(1):e53723. http://dx.doi.org/10.1371/ journal.pone. 0053723

De Benedictis, L., S. Nenci, G. Santoni, L. Tajoli, and C. Vicarelli. 2014. Network analysis of world trade using the BACI-CEPII dataset. Global Economy Journal 14(3-4):287-343. http://dx.doi. org/10.1515/gej-2014-0032
DeFries, R. S., T. Rudel, M. Uriarte, and M. Hansen. 2010. Deforestation driven by urban population growth and agricultural trade in the twenty-first century. Nature Geoscience 3(3):178-181. http://dx.doi.org/10.1038/ngeo756

Deines, J. M., X. Liu, and J. Liu. 2016. Telecoupling in urban water systems: an examination of Beijing's imported water supply. Water International 41(2):251-270. http://dx.doi. org/10.1080/02508060.2015.1113485

del Río-Chanona, R. M., J. Grujić, and H. Jeldtoft Jensen. 2017. Trends of the world input and output network of global trade. PLoS ONE 12(1):e0170817. http://dx.doi.org/10.1371/journal. pone. 0170817

Department of Economic and Social Affairs Statistics Division. 2010. International merchandise trade statistics: concepts and definitions. United Nations, New York, New York, USA.

Dong, B., W. Wei, X. Ma, and P. Li. 2018. On the impacts of carbon tax and technological progress on China. Applied Economics 50(4):389-406. http://dx.doi.org/10.1080/00036846.2$\underline{017.1316826}$

Dou, Y., R. Silva, H. Yang, and J. Liu. 2018. Spillover effect offsets the conservation effort in the Amazon. Journal of Geographical Sciences 28(11):1715-1732. http://dx.doi.org/10.1007/s11442-018-1539-0

Eakin, H., R. S. Defries, S. Kerr, E. F. Lambin, J. Liu, P. J. Marcotullio, P. Messerli, A. Reenberg, X. Rueda, S. R. Swaffield, B. Wicke, K. Zimmerer, S. R. Swaffield, B. Wicke, and K. Zimmerer. 2014. Significance of telecoupling for exploration of land-use change. Pages 141-162 in K. C. Seto and A. Reenberg, editors. Rethinking global land use in an urban era. MIT Press, Cambridge, Massachusetts, USA. http://dx.doi.org/10.7551/ mitpress/9780262026901.003.0008

Fahrig, L. 2003. Effects of habitat fragmentation on biodiversity. Annual Review of Ecology, Evolution, and Systematics 34:487-515. http://dx.doi.org/10.1146/annurev.ecolsys.34.011802.132419

Fang, B., Y. Tan, C. Li, Y. Cao, J. Liu, P. Schweizer, H. Shi, B. Zhou, H. Chen, and Z. Hu. 2016. Energy sustainability under the framework of telecoupling. Energy 106:253-259. http://dx.doi. org/10.1016/j.energy.2016.03.055

Fearnside, P. M. 2001. Soybean cultivation as a threat to the environment in Brazil. Environmental Conservation 28(1):23-38. http://dx.doi.org/10.1017/S0376892901000030

Fitzherbert, E. B., M. J. Struebig, A. Morel, F. Danielsen, C. A. Brühl, P. F. Donald, and B. Phalan. 2008. How will oil palm expansion affect biodiversity? Trends in Ecology \& Evolution 23 (10):538-545. http://dx.doi.org/10.1016/j.tree.2008.06.012

Flaskerud, G. 2003. Brazil's soybean production and impact. North Dakota State University Extension Service, Fargo, North Dakota, USA.

Fletcher, R. J., B. A. Robertson, J. Evans, P. J. Doran, J. R. R. Alavalapati, and D. W. Schemske. 2011. Biodiversity conservation in the era of biofuels: risks and opportunities. Frontiers in Ecology and the Environment 9(3):161-168. http://dx.doi.org/10.1890/090091

Foley, J. A., R. Defries, G. P. Asner, C. Barford, G. Bonan, S. R. Carpenter, F. S. Chapin, M. T. Coe, G. C. Daily, H. K. Gibbs, J. 
H. Helkowski, T. Holloway, E. A. Howard, C. J. Kucharik, C. Monfreda, J. A. Patz, I. C. Prentice, N. Ramankutty, and P. K. Snyder. 2005. Global consequences of land use. Science 309 (5734):570-574. http://dx.doi.org/10.1126/science.1111772

Food and Agriculture Organization of the United Nations. 2016. FAOSTAT database. FAO, Rome, Italy. [online] URL: http:// www.fao.org/faostat

Ford, A. 2010. Modeling the environment. Second edition. Island, Washington, D.C., USA.

Fortin, M.-J., P. M. A. James, A. MacKenzie, S. J. Melles, and B. Rayfield. 2012. Spatial statistics, spatial regression, and graph theory in ecology. Spatial Statistics 1:100-109. http://dx.doi. org/10.1016/j.spasta.2012.02.004

Fortunato, S. 2010. Community detection in graphs. Physics Reports 486(3-5):75-174. http://dx.doi.org/10.1016/j.physrep.2009.11.002

Fracasso, A. 2014. A gravity model of virtual water trade. Ecological Economics 108:215-228. http://dx.doi.org/10.1016/j. ecolecon.2014.10.010

Friis, C., J. Ø. Nielsen, I. Otero, H. Haberl, P. Hostert, and J. Niewöhner. 2016. From teleconnection to telecoupling: taking stock of an emerging framework in land system science. Journal of Land Use Science 11(2):131-153. http://dx.doi. org/10.1080/1747423X.2015.1096423

Gasparri, N. I., T. Kuemmerle, P. Meyfroidt, Y. le Polain de Waroux, and H. Kreft. 2015. The emerging soybean production frontier in Southern Africa: conservation challenges and the role of south-south telecouplings. Conservation Letters 9(1):21-31. http://dx.doi.org/10.1111/conl.12173

Gibbs, H. K., L. Rausch, J. Munger, I. Schelly, D. Morton, P. Noojipady, B. Soares-Filho, P. Barreto, L. Micol, and N. F. Walker. 2015. Brazil's soy moratorium. Science 347(6220):3-5. http://dx.doi.org/10.1126/science.aaa0181

Gibson, L., T. M. Lee, L. P. Koh, B. W. Brook, T. A. Gardner, J. Barlow, C. A. Peres, C. J. A. Bradshaw, W. F. Laurance, T. E. Lovejoy, and N. S. Sodhi. 2011. Primary forests are irreplaceable for sustaining tropical biodiversity. Nature 478(7369):378-381. http://dx.doi.org/10.1038/nature10425

Girvan, M., and M. E. J. Newman. 2002. Community structure in social and biological networks. Proceedings of the National Academy of Sciences 99(12):7821-7826. http://dx.doi.org/10.1073/ pnas. 122653799

Gonzalez, A. 2009. Metacommunities: spatial community ecology. Encyclopedia of Life Sciences. John Wiley \& Sons, Hoboken, New Jersey, USA http://dx.doi.org/10.1002/9780470015902. $\underline{\mathrm{a} 0021230}$

Grace, J. B. 2006. Structural equation modeling and natural systems. Cambridge University Press, Cambridge, UK. http://dx. doi.org/10.1017/CBO9780511617799

Graesser, J., T. M. Aide, H. R. Grau, and N. Ramankutty. 2015. Cropland/pastureland dynamics and the slowdown of deforestation in Latin America. Environmental Research Letters 10(3):034017. http://dx.doi.org/10.1088/1748-9326/10/3/034017
Hansen, M. C., P. V. Potapov, R. Moore, M. Hancher, S. A. Turubanova, A. Tyukavina, D. Thau, S. V. Stehman, S. J. Goetz, T. R. Loveland, A. Kommareddy, A. Egorov, L. Chini, C. O. Justice, and J. R. G. Townshend. 2013. High-resolution global maps of 21st-century forest cover change. Science 342 (6160):850-853. http://dx.doi.org/10.1126/science.1244693

Hanson, G. H. 2012. The rise of middle kingdoms: emerging economies in global trade. Journal of Economic Perspectives 26 (2):41-64. http://dx.doi.org/10.1257/jep.26.2.41

HighQuest Partners and Soyatech. 2011. How the global oilseed and grain trade works. U.S. Soybean Export Council, St. Louis, Missouri, USA.

Holland, P. W., and S. Leinhardt. 1981. An exponential family of probability distributions for directed graphs. Journal of the American Statistical Association 76(373):33-50. http://dx.doi. org/10.1080/01621459.1981.10477598

Hulina, J., C. Bocetti, H. Campa III, V. Hull, W. Yang, and J. Liu. 2017. Telecoupling framework for research on migratory species in the Anthropocene. Elementa Science of the Anthropocene 5:5. http://dx.doi.org/10.1525/elementa.184

Hunter, D. R., M. S. Handcock, C. T. Butts, S. M. Goodreau, and M. Morris. 2008. ergm: A package to fit, simulate and diagnose exponential-family models for networks. Journal of Statistical Software 24(3):1-29. http://dx.doi.org/10.18637/jss.v024.i03

Iapadre, P. L., and L. Tajoli. 2014. Emerging countries and trade regionalization. A network analysis. Journal of Policy Modeling 36:S89-S110. http://dx.doi.org/10.1016/j.jpolmod.2013.10.010

International Monetary Fund. 2011. Changing patterns of global trade. International Monetary Fund, Washington, D.C., USA.

Kastner, T., A. Schaffartzik, N. Eisenmenger, K.-H. Erb, H. Haberl, and F. Krausmann. 2014. Cropland area embodied in international trade: contradictory results from different approaches. Ecological Economics 104:140-144. http://dx.doi. org/10.1016/j.ecolecon.2013.12.003

Kempe, D., J. Kleinberg, and A. Kumar. 2002. Connectivity and inference problems for temporal networks. Journal of Computer and System Sciences 64(4):820-842. http://dx.doi.org/10.1006/ jess.2002.1829

Kline, R. B. 2011. Principles and practice of structural equation modeling. Guilford, New York, New York, USA.

Krackhardt, D. 1994. Graph theoretical dimensions of informal organizations. Computational Organization Theory 89(112):123-140.

Lathuillière, M. J., M. S. Johnson, G. L. Galford, and E. G. Couto. 2014. Environmental footprints show China and Europe's evolving resource appropriation for soybean production in Mato Grosso, Brazil. Environmental Research Letters 9(7):074001. http://dx.doi.org/10.1088/1748-9326/9/7/074001

Lee, J. Y., and M.-P. Kwan. 2011. Visualisation of socio-spatial isolation based on human activity patterns and social networks in space-time. Tijdschrift voor economische en sociale geografie 102(4):468-485. http://dx.doi.org/10.1111/j.1467-9663.2010.00649. $\underline{\mathrm{x}}$ 
Lentz, H. H. K., A. Koher, P. Hövel, J. Gethmann, C. SauterLouis, T. Selhorst, and F. J. Conraths. 2016. Disease spread through animal movements: a static and temporal network analysis of pig trade in Germany. PLoS ONE 11(5):e0155196. http://dx.doi.org/10.1371/journal.pone.0155196

Lenzen, M., D. Moran, K. Kanemoto, B. Foran, L. Lobefaro, and A. Geschke. 2012. International trade drives biodiversity threats in developing nations. Nature 486(7401):109-112. http:// dx.doi.org/10.1038/nature11145

Li, Z., H. Dai, L. Sun, Y. Xie, Z. Liu, P. Wang, and H. Yabar. 2018. Exploring the impacts of regional unbalanced carbon tax on $\mathrm{CO}_{2}$ emissions and industrial competitiveness in Liaoning province of China. Energy Policy 113:9-19. http://dx.doi. org/10.1016/j.enpol.2017.10.048

Liu, J. 2017. Integration across a metacoupled world. Ecology and Society 22(4):29. http://dx.doi.org/10.5751/ES-09830-220429

Liu, J., T. Hertel, E. Moran, A. Viña, and S. Nichols. $2015 a$. Complex dynamics of telecoupled human and natural systems. U. S. National Science Foundation, Alexandria, Virginia, USA.

Liu, J., V. Hull, M. Batistella, R. DeFries, T. Dietz, F. Fu, T. W. Hertel, R. C. Izaurralde, E. F. Lambin, S. Li, L. A. Martinelli, W. J. McConnell, E. F. Moran, R. Naylor, Z. Ouyang, K. R. Polenske, A. Reenberg, G. de Miranda Rocha, C. S. Simmons, P. H. Verburg, P. M. Vitousek, F. Zhang, and C. Zhu. 2013. Framing sustainability in a telecoupled world. Ecology and Society 18 (2):26. http://dx.doi.org/10.5751/ES-05873-180226

Liu, J., V. Hull, J. Luo, W. Yang, W. Liu, A. Viña, C. Vogt, Z. Xu, H. Yang, J. Zhang, L. An, X. Chen, S. Li, Z. Ouyang, W. Xu, and H. Zhang. 2015b. Multiple telecouplings and their complex interrelationships. Ecology and Society 20(3):44. http://dx.doi. org/10.5751/ES-07868-200344

Liu, J., H. Mooney, V. Hull, S. J. Davis, J. Gaskell, T. Hertel, J. Lubchenco, K. C. Seto, P. Gleick, C. Kremen, and S. Li. 2015 c. Systems integration for global sustainability. Science 347 (6225):1258832. http://dx.doi.org/10.1126/science.1258832

Liu, J., W. Yang, and S. Li. 2016. Framing ecosystem services in the telecoupled Anthropocene. Frontiers in Ecology and the Environment 14(1):27-36. http://dx.doi.org/10.1002/16-0188.1

Lü, L., and T. Zhou. 2011. Link prediction in complex networks: a survey. Physica A: Statistical Mechanics and its Applications 390 (6):1150-1170. http://dx.doi.org/10.1016/j.physa.2010.11.027

Macedo, M. N., R. S. DeFries, D. C. Morton, C. M. Stickler, G. L. Galford, and Y. E. Shimabukuro. 2012. Decoupling of deforestation and soy production in the southern Amazon during the late 2000s. Proceedings of the National Academy of Sciences 109(4):1341-1346. http://dx.doi.org/10.1073/pnas.1111374109

Mastrandrea, R., T. Squartini, G. Fagiolo, and D. Garlaschelli. 2014. Reconstructing the world trade multiplex: the role of intensive and extensive biases. Physical Review E 90(062804). http://dx.doi.org/10.1103/PhysRevE.90.062804

Mikusiński, G., M. Blicharska, H. Antonson, M. Henningsson, G. Göransson, P. Angelstam, and A. Seiler. 2013. Integrating ecological, social and cultural dimensions in the implementation of the landscape convention. Landscape Research 38(3):384-393. http://dx.doi.org/10.1080/01426397.2011.650629
Minor, E. S., and T. R. Lookingbill. 2010. A multiscale network analysis of protected-area connectivity for mammals in the United States. Conservation Biology 24(6):1549-1558. http://dx. doi.org/10.1111/j.1523-1739.2010.01558.X

Moran, D., and K. Kanemoto. 2017. Identifying species threat hotspots from global supply chains. Nature Ecology \& Evolution 1:23. http://dx.doi.org/10.1038/s41559-016-0023

Morris, M., M. S. Handcock, and D. R. Hunter. 2008. Specification of exponential-family random graph models: terms and computational aspects. Journal Of Statistical Software 24 (4):1548-7660. http://dx.doi.org/10.18637/jss.v024.i04

Nepstad, D. C., C. M. Stickler, and O. T. Almeida. 2006. Globalization of the Amazon soy and beef industries: opportunities for conservation. Conservation Biology 20 (6):1595-1603. http://dx.doi.org/10.1111/j.1523-1739.2006.00510.

\section{$\underline{x}$}

Newman, M. E. J. 2001. Clustering and preferential attachment in growing networks. Physical Review E 64(2):4. http://dx.doi. org/10.1103/PhysRevE.64.025102

Newman, M. E. J. 2003. Mixing patterns in networks. Physical Review E 67(2):13. http://dx.doi.org/10.1103/PhysRevE.67.026126

Newman, M. E. J. 2004. Detecting community structure in networks. European Physical Journal B 38(2):321-330. http://dx. doi.org/10.1140/epjb/e2004-00124-y

Penuel, W. R., M. Sun, K. A. Frank, and H. A. Gallagher. 2012. Using social network analysis to study how collegial interactions can augment teacher learning from external professional development. American Journal of Education 119(1):103-136. http://dx.doi.org/10.1086/667756

Possamai, J. P., A. Pescador, S. F. Mayerle, and J. Neiva de Figueiredo. 2015. Optimal commodity price stabilization as a multi-period spatial equilibrium problem: a supernetwork approach with public buffer stocks. Transportation Research Part E: Logistics and Transportation Review 77:289-310. http://dx.doi. org/10.1016/j.tre.2015.03.004

R Core Team. 2017. R: a language and environment for statistical computing. R Foundation for Statistical Computing, Vienna, Austria.

Rathwell, K. J., and G. D. Peterson. 2012. Connecting social networks with ecosystem services for watershed governance: a social-ecological network perspective highlights the critical role of bridging organizations. Ecology and Society 17(2):24. http:// dx.doi.org/10.5751/ES-04810-170224

Reenberg, A., and N. A. Fenger. 2011. Globalizing land use transitions: the soybean acceleration. Geografisk TidsskriftDanish Journal of Geography 111(1):85-92. http://dx.doi. org/10.1080/00167223.2011.10669524

Rosa, I. M. D., C. Souza, and R. M. Ewers. 2012. Changes in size of deforested patches in the Brazilian Amazon. Conservation Biology 26(5):932-937. http://dx.doi.org/10.1111/j.1523-1739.2012.01901. $\underline{\mathrm{X}}$

Roy, J. R., and G. J. D. Hewings. 2009. Regional input-output with endogenous internal and external network flows. Pages 161-176 in C. Karlsson, A. E. Andersson, P. C. Cheshire, and R. 
R. Stough, editors. New directions in regional economic development. Springer, Dordrecht, The Netherlands. http://dx. doi.org/10.1007/978-3-642-01017-0 10

Rudel, T. K., R. Defries, G. P. Asner, and W. F. Laurance. 2009. Changing drivers of deforestation and new opportunities for conservation. Conservation Biology 23(6):1396-1405. http://dx. doi.org/10.1111/j.1523-1739.2009.01332.x

Schiller, F., A. S. Penn, and L. Basson. 2014. Analyzing networks in industrial ecology - a review of Social-Material Network Analyses. Journal of Cleaner Production 76:1-11. http://dx.doi. org/10.1016/j.jclepro.2014.03.029

Schloerke, B., J. Crowley, D. Cook, F. Briatte, M. Marbach, E. Thoen, A. Elberg, and J. Larmarange. 2016. GGally: Extension to "ggplot2."

Seaquist, J. W., E. L. Johansson, and K. A. Nicholas. 2014. Architecture of the global land acquisition system: applying the tools of network science to identify key vulnerabilities. Environmental Research Letters 9(11):114006. http://dx.doi. org/10.1088/1748-9326/9/11/114006

Shen, B., J. Zhang, Y. Li, Q. Zheng, and X. Li. 2015. International trade modelling using open flow networks: a flow-distance based analysis. PLoS ONE 10(11):e0142936. http://dx.doi.org/10.1371/ journal.pone. 0142936

Shutters, S. T., and R. Muneepeerakul. 2012. Agricultural trade networks and patterns of economic development. PLoS ONE 7 (7):e39756. http://dx.doi.org/10.1371/journal.pone.0039756

Sinclair, T. R., H. Marrou, A. Soltani, V. Vadez, and K. C. Chandolu. 2014. Soybean production potential in Africa. Global Food Security 3(1):31-40. http://dx.doi.org/10.1016/j.gfs.2013.12.001

Sun, J., H. Mooney, W. Wu, H. Tang, Y. Tong, Z. Xu, B. Huang, Y. Cheng, X. Yang, D. Wei, F. Zhang, and J. Liu. 2018. Importing food damages domestic environment: evidence from global soybean trade. Proceedings of the National Academy of Sciences 115(21):5415-5419. http://dx.doi.org/10.1073/pnas.1718153115

Sun, J., W. Wu, H. Tang, and J. Liu. 2015. Spatiotemporal patterns of non-genetically modified crops in the era of expansion of genetically modified food. Scientific Reports 5:14180. http://dx. doi.org/10.1038/srep14180

Tamea, S., J. A. Carr, F. Laio, and L. Ridolfi. 2014. Drivers of the virtual water trade. Water Resources Research 50(1):17-28. http://dx.doi.org/10.1002/2013WR014707

Taylor, P. D., L. Fahrig, K. Henein, and G. Merriam. 1993. Connectivity is a vital element of landscape structure. Oikos 68 (3):571-573. http://dx.doi.org/10.2307/3544927

The World Bank. 2017. World Bank country and lending groups. The World Bank, Washington, D.C., USA. [online] URL: https:// datahelpdesk.worldbank.org/knowledgebase/articles/906519-worldbank-country-and-lending-groups

Tonini, F., and J. Liu. 2017. Telecoupling toolbox: spatiallyexplicit tools for studying telecoupled human and natural systems. Ecology and Society 22(4):11. http://dx.doi.org/10.5751/ ES-09696-220411
Torres, A., J. Brandt, K. Lear, and J. Liu. 2017. A looming tragedy of the sand commons. Science 357(6355):970-971 http://dx.doi. org/10.1126/science.aao0503

Tuninetti, M., S. Tamea, F. Laio, and L. Ridolfi. 2017. To trade or not to trade: link prediction in the virtual water network. Advances in Water Resources 110:528-537. http://dx.doi. org/10.1016/j.advwatres.2016.08.013

Turner, M. G. 2005. Landscape ecology: What is the state of the science? Annual Review of Ecology, Evolution, and Systematics 36 (1):319-344. http://dx.doi.org/10.1146/annurev.ecolsys.36.102003.152614

Turner, M. G., R. V O'Neill, R. H. Gardner, and B. T. Milne. 1989. Effects of changing spatial scale on the analysis of landscape pattern. Landscape Ecology 3(3-4):153-162. http://dx.doi. org/10.1007/BF00131534

Urban, D., and T. Keitt. 2001. Landscape connectivity: a graphtheoretic perspective. Ecology 82(5):1205-1218. http://dx.doi. org/10.1890/0012-9658(2001)082[1205:LCAGTP]2.0.CO;2

Vittor, A. Y., R. H. Gilman, J. Tielsch, G. Glass, T. Shields, W. Sánchez Lozano, V. Pinedo-Cancino, and J. A. Patz. 2006. The effect of deforestation on the human-biting rate of Anopheles darlingi, the primary vector of Falciparum Malaria in the Peruvian Amazon. American Journal of Tropical Medicine and Hygiene 74(1):3-11. http://dx.doi.org/10.4269/ajtmh.2006.74.3

Wasserman, S., and K. Faust. 1994. Social network analysis: methods and applications. Cambridge, University Press, Cambridge, UK. http://dx.doi.org/10.1017/CBO9780511815478

Wickham, H. 2009. ggplot2: Elegant graphics for data analysis. Springer, New York, New York, USA.

Wiens, J. A. 1989. Spatial scaling in ecology. Functional Ecology 3(4):385-397. http://dx.doi.org/10.2307/2389612

Yang, D., J. Cai, V. Hull, K. Wang, Y. Tsang, and J. Liu. 2016. New road for telecoupling global prosperity and ecological sustainability. Ecosystem Health and Sustainability 2(10):e01242. http://dx.doi.org/10.1002/ehs2.1242

Zhu, H., Y. Tang, C. Peng, and K. Yu. 2018. The heterogeneous response of the stock market to emission allowance price: evidence from quantile regression. Carbon Management 9 (3):277-289. http://dx.doi.org/10.1080/17583004.2018.1475802

Zhu, Y.-X., X.-G. Zhang, G.-Q. Sun, M. Tang, T. Zhou, and Z.K. Zhang. 2014. Influence of reciprocal links in social networks. PLoS ONE 9(7):e103007. http://dx.doi.org/10.1371/journal. pone. 0103007 
Appendix 1. Pantropical countries included in analysis of social-ecological linkages in the soybean metacoupled system $2000-2012$.

Please click here to download file 'appendix1.pdf'. 
Ecology and Society 23(4): 3

https://www.ecologyandsociety.org/vol23/iss4/art3/

Appendix 2. Clique count results

Please click here to download file 'appendix2.pdf'. 
Ecology and Society 23(4): 3

https://www.ecologyandsociety.org/vol23/iss4/art3/

Appendix 3. Clique comembership results (2013).

Please click here to download file 'appendix3.xlsx'. 
Ecology and Society 23(4): 3

https://www.ecologyandsociety.org/vol23/iss4/art3/

Appendix 4. Clique comembership results (1986-2013)

Please click here to download file 'appendix4.xlsx'. 
Ecology and Society 23(4): 3

https://www.ecologyandsociety.org/vol23/iss4/art3/

Appendix 5. Positive feedback in soybean trade relationships, as measured by regression of sending and receiving values relative to time.

Please click here to download file 'appendix 5.xlsx'. 
Ecology and Society 23(4): 3

https://www.ecologyandsociety.org/vol23/iss4/art3/

Appendix 6. Supporting information for Figure 6, including social and ecological attributes of soybean trading countries in the pantropics.

Please click here to download file 'appendix6.pdf'. 